\title{
Revision of the Australian genus Blaena (Heteroptera: Cydnidae)
}

\author{
JERZY A. LIS ${ }^{1}$ and JOANNA HEYNA ${ }^{2}$ \\ Department of Biosystematics, Division of Zoology, University of Opole, Oleska 22, 45-052 Opole, Poland; e-mail: \\ 'cydnus@uni.opole.pl; ${ }^{2}$ heyna@uni.opole.pl
}

Key words. Hemiptera, Heteroptera, Cydnidae, Blaena, revision, key new species, Australia

\begin{abstract}
A revision of species of the Australian burrower bug genus Blaena Walker, 1868 is presented. Eight previously known species are redescribed and four new ones, B. hirta n. sp. (Queensland), B. parathroposa $\mathrm{n}$. sp. (Queensland), B. pseudosetosa $\mathrm{n}$. sp. (Western Australia), and B. serrata n. sp. (Northern Territory, Queensland, Western Australia) are described and illustrated. The male and female genitalia of all the species of the genus are studied for the first time. A key for species determination is also provided.
\end{abstract}

\section{INTRODUCTION}

The genus Blaena was erected by Walker (1868) for a new species, Blaena setosa, from an unknown locality. Over a dozen years later Signoret (1880a) described Macrhymenus membranaceus from Australia, a genus and species new to science. Distant (1899), after studying the type specimen of Blaena setosa Walker, treated it as a senior synonym of Signoret's species.

More than sixty years later, Froeschner (1960) redescribed the genus and described four new species, followed by two additional ones (Froeschner 1966). Recently, Lis (1999a) described Blaena tamasi, the first burrower bug species with staphylinoid wing modification.

Thus, till now the genus contained eight species (Lis, 1996, 1999b) distributed only in the Australian continent. The present paper includes their redescriptions, as well as descriptions of four species new to the science, and a key. Moreover, the male and female genitalia are studied for the first time for all species of the genus.

Illustrations were made using a drawing attachement connected to an Olympus SZH-10 stereomicroscope; male paramere (left) were figured in dorsal, ventral and posterior views, male pygophore and female ovipositor were illustrated with ventral side down and dorsal side up. All measurements are in millimeters.

The source of material for this study were the following institutional collections (the acronyms are used in the text): BMNH - Natural History Museum, London, Great Britain; BPBM - Bernice P. Bishop Museum, Honolulu, Hawaii, USA; QPIM - Department of Primary Industries, Mareeba, Queensland, Australia; HNHM - Hungarian Natural History Museum, Budapest, Hungary; NHMW Naturhistorisches Museum, Wien, Austria; ANIC - Australian National Insect Collection, Canberra, Australia; MVNH - Museum of Victoria, Natural History, Melbourne, Australia; NMPC - National Museum of Natural History, Department of Entomology, Prague, Czech Republic; MAGD - Museums and Art Galleries of the Northern Territory, Darwin, Australia; QMBA -
Queensland Museum, Brisbane, Australia; SAMA - South Australian Museum, Adelaide, Australia; UQIC Queensland University Insect Collection, Brisbane, Australia; WAMP - Western Australian Museum, Perth, Australia; ZMAS - Zoological Institute, Russian Academy of Sciences, St. Petersburg, Russia; DBUO - University of Opole, Department of Biosystematics, Opole, Poland.

\section{GENUS BLAENA WALKER, 1868}

Blaena Walker, 1868: 537. Type species by monotypy: Blaena setosa Walker, 1868.

Macrhymenus Signoret, 1880a: 25 [1880b: XVII, as Macrymenus] (syn. by Distant, 1899: 224). Type species by monotypy: Macrhymenus membranaceus Signoret, 1880 (= Blaena setosa Walker, 1868).

\section{Diagnostic characters}

Body medium sized, elongate, sides subparallel; dorsum flattened to weakly convex. Lateral margins of head more or less diverging from preocular emarginations; submargins with setigerous punctures bearing hair-like setae, but no pegs and peg-like setae; paraclypei longer than clypeus and joined in front of the latter; eyes small, stylated; ocelli very small; antennae 5 -segmented, segments cylindrical. Pronotum broader than long, almost subquadrate in outline; disc coarsely and densely punctured; anterior margin concave; lateral margins entire or serrated, submargins with a row of setigerous punctures bearing long hair-like setae. Scutellum broader than long, subtriangular, bearing distinct lateral depressions on either side of disc. Corium short, divided into clavus, meso- and exocorium in macropterous and brachypterous forms, undivided into parts in forms with staphylinoid wing modification; membrane large, nearly two-thirds of hemelytral length, in forms with staphylinoid wing modification membrane strongly reduced; costa with or without setigerous punctures. Propleuron densely punctured; evaporative areas well defined; apex of peritreme polished, elongated, not recurved posteriorly. Posterior tibiae simple or modified (usually in male sex). 


\section{Note}

This genus belongs to the tribe Cydnini (as defined by Lis, 1994); it is easily recognizable from all other Australian genera of the tribe by the characters given in the key by Lis (1997).

\section{Blaena blothroposa Froeschner, 1966}

\section{(Figs 1-9)}

Blaena blothroposa Froeschner, 1966: 690; Lis, 1995: 138, 1996: 183.

\section{Redescription}

Body. Length 4.15-4.88 (female), 5.25-5.40 (male).

Head (Fig. 1). Black, shining, punctured and bearing gold, erect hairs of different lengths; lateral margins narrowed anteriorly; paraclypei longer than clypeus and joined anteriorly; the latter somewhat convex, bare; each paraclypeus with a submarginal row of 4-5 long hair-like setae; bucculae bearing fine hairs; ocular index 3.50-3.70; ocelli small, the distance between ocelli about 2.6-2.9 times longer than the distance between an ocellus and the eye, ocellar index 8.0-11.0; rostrum extending beyond anterior coxae; length of antennal segments: I $0.24-0.25$, II $0.24-0.32$, III $0.42-0.50$, IV $0.60-0.66$, V $0.64-0.68$

Prothorax. Pronotum black, shining, densely coarsely punctured, about 1.5-1.6 times broader than long (Fig. 2); its dorsal surface bearing numerous golden hairs; anterior and posterior margins broadly concave; lateral margins not serrated, almost parallel, sometimes narrowed in the middle; each submargin with a row of 14-15 long hairlike setae; transverse postmedial impression shallow, hardly visible. Prosternum black or blackish brown, punctured; prosternal carinae low, bare or with single hairs. Propleuron black, shining, coarsely punctured, its anterior margin bare, lateral parts shallowly punctured and sparsely pilose.

Mesothorax. Scutellum black with apex more brown than its base, width slightly larger than the length, punctation of disc crowded and coarse, median discal carina hardly visible; pilosity of scutellar disc sparser than that of pronotum. Anterior part of mesopleuron punctured, evaporative area narrow (Fig. 7). Corium brown or dark brown, costal margin with 7-9 setigerous punctures bearing hair-like setae; membrane normally developed, not reaching the tip of abdomen, veins reticulate, darker than the remaining surface of membrane.

Metathorax. Metapleural evaporatorium small, not reaching half length of metapleuron (Fig. 7), peritreme elongated.

Legs. Anterior pair castaneous, shining, bearing numerous erect golden-brown hairs; anterior tibiae somewhat lighter than femora, broadened apically. Femora of middle pair with about seven small acute tubercles on the ventral margin in males, or with small blunt tubercles in females; tibiae straight with black spines. Male hind femora ventrally with a row of strong spines (Fig. 3); female hind femora ventrally with a row of short blunt spines; male hind tibiae slightly curved apically (Fig. 3), female hind tibiae straight.

Abdomen. Sterna not impressed sublaterally, entirely coarsely punctured in female, broad lateral impunctate band on visible segments III and IV present in male; lateral margins of each segment with a row of 4-5 setigerous punctures bearing long hair-like setae, and well-developed posteriorly projecting spine. Sterna bearing erect golden-brown hairs, especially numerous close to lateral margins. Male genital capsule as in Fig. 8, paramere as in Figs 4-6. Female genital plates narrow (Fig. 9), densely punctate.

Material examined.VICTORIA: Paratype male: Australia, Victoria, Inglewood, T-8038, Blaena blothroposa det. R.C. Froeschner (MVNH); SOUTH AUSTRALIA: 1 female, Muston, Pelican Lagoon, Kangaroo Island, from soil in thick scrub, 15 July 1964, T.J. Cooper (SAMA); 1 female, Wallaroo N., Beach Sandhills, 30 Jan. 1964, G.F. Gross (SAMA); 1 female, $25 \mathrm{~km}$ SSW Mabel Ck. H.S., Watercourse, 29.10'0" 134.14'30", 29 Oct. 1984, CRA Survey (DBUO).

Distribution. South Australia (first record), Victoria.

\section{Blaena cirra Froeschner, 1966}

(Figs 10-18)

Blaena cirra Froeschner, 1966: 692; Lis, 1995: 138, 1996: 183 .

\section{Redescription}

Body. Length 4.25-4.80 (female), 3.65-4.75 (male).

Head (Fig. 10). Black or dark brown, paraclypei coarsely punctured and bearing gold, erect hairs of different lengths; lateral margins conspicuously narrowed anteriorly; paraclypei longer than clypeus and joined anteriorly; clypeus somewhat convex, bare; each paraclypeus with a submarginal row of 5-6 long hair-like setae; bucculae bearing fine hairs; ocular index 3.21-3.60 (male), 3.71-4.01 (female); ocelli small, distance between ocelli about 2.8-3.6 times longer than the distance between an ocellus and the eye, ocellar index 6.1-10.8; rostrum extending beyond anterior coxae; antennal segments I to IV progressively longer, $\mathrm{V}$ segment as long as or shorter than IV.

Prothorax. Pronotum about 1.6-1.8 times broader than long (Fig. 11), black or dark brown, margins somewhat lighter than a disc, the latter densely coarsely punctured; dorsal surface of disc bearing golden hairs; anterior margin broadly concave, posterior margin shallowly concave in its middle; lateral margins not serrated, each submargin with a row of 18-20 long hair-like setae; transverse postmedial impression shallow. Prosternum black or blackish brown, punctured; prosternal carinae vague, bearing golden woolly hairs. Propleuron black or dark brown, coarsely punctured, its anterior margin densely covered with golden woolly hairs, lateral parts sparsely, shallowly punctured and finely pilose.

Mesothorax. Scutellum blackish brown or dark castaneous, slightly wider than long, punctation of disc as dense as that of pronotum, median discal carina welldeveloped; scutellar disc bearing numerous hairs over its 

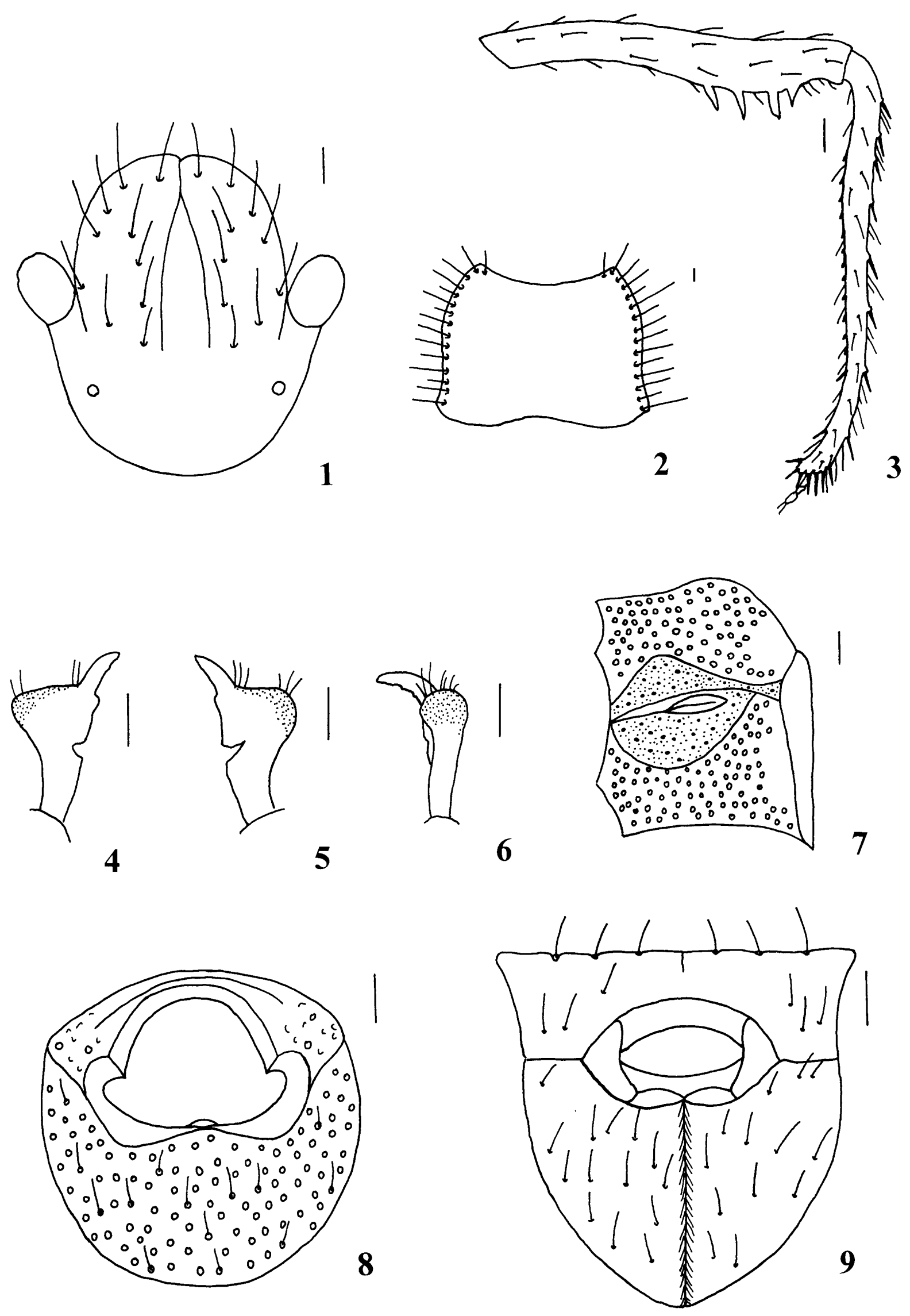

Figs 1-9. Blaena blothroposa Froeschner. 1 - head; 2 - pronotum; 3 - male hind leg; 4-6 - various views of paramere; 7 evaporatoria on meso- and metapleuron; 8 - male genital capsule; 9 - female genital plates. Scale: $0.1 \mathrm{~mm}$. 

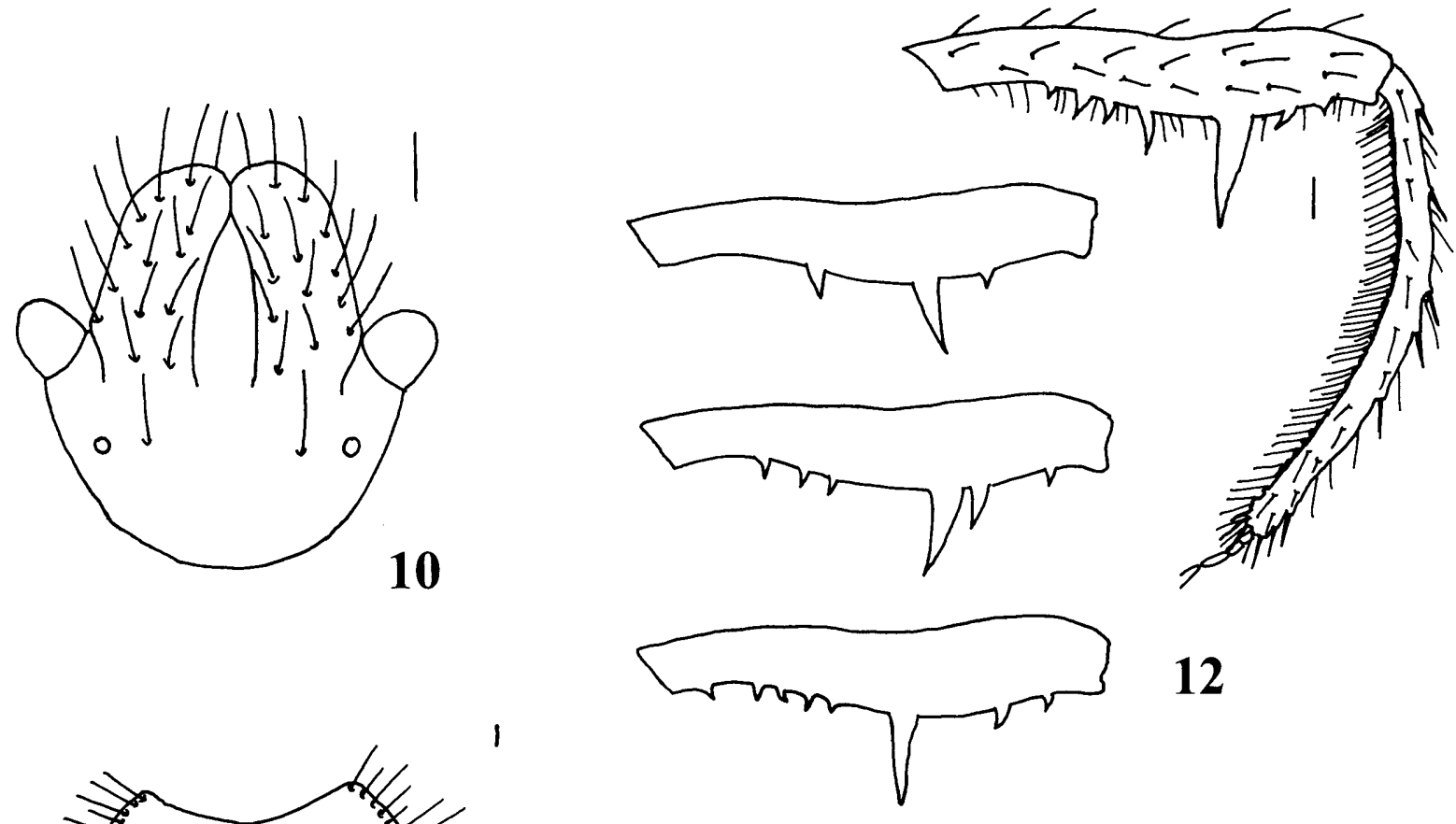

12

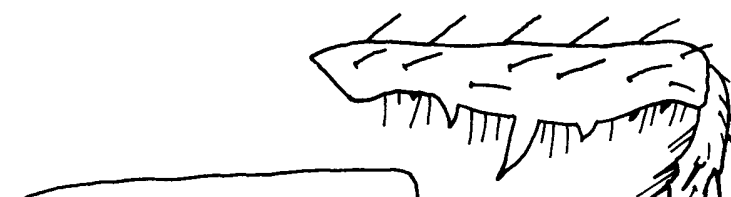

11
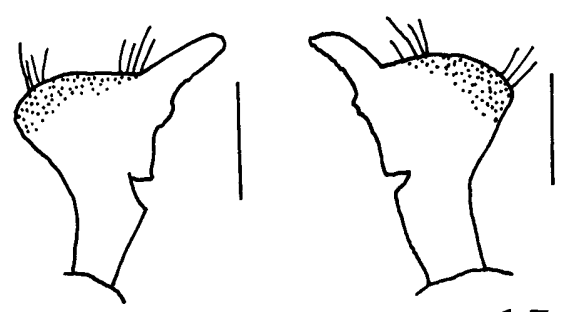

15
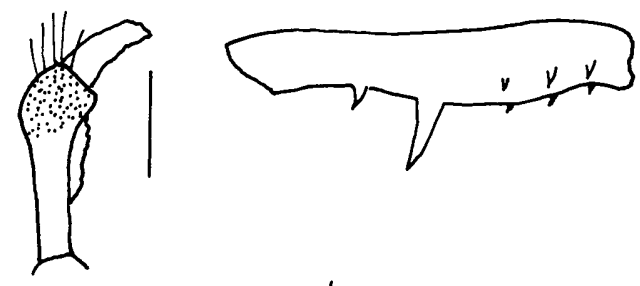

\section{3}

14

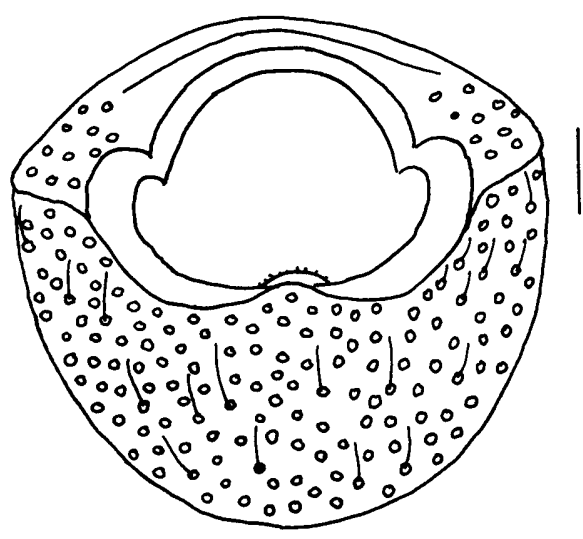

17

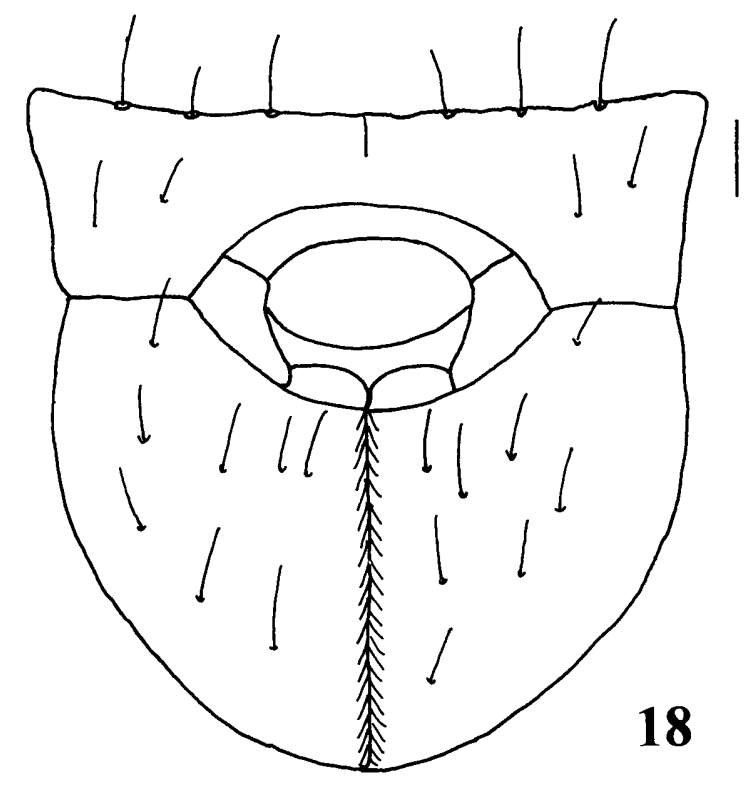

Figs 10-18. Blaena cirra Froeschner. 10 - head; 11 - pronotum; 12 - male hind leg, and variability in the arrangement of spines on femur; 13 - male middle leg, and variability in the arrangement of spines on femur; $14-16$ - various views of paramere; 17 male genital capsule; 18 - female genital plates. Scale: $0.1 \mathrm{~mm}$. 
entire surface. Anterior part of mesopleuron punctured, evaporative area rounded, elongated. Corium castaneous or dark castaneous, costal margin with $12-15$ setigerous punctures bearing long hair-like setae; membrane normally developed, narrower than abdomen, reaching or almost reaching its tip, veins usually straight, sometimes branched; base of membrane usually with two pale patches.

Metathorax. Metapleural evaporatorium large, nearly two thirds of metapleuron length, peritreme elongated.

Legs. Anterior pair castaneous or brown, bearing numerous erect light hairs; anterior tibiae apically broadened. Femora of middle pair with a row of sharp spines, among these one or two very large in male (Fig. 13), female middle femora unmodified; tibiae straight with black spines. Male hind femora ventrally with a row of sharp spines, among which one or two are clearly longer than others (Fig. 12); female hind femora ventrally without such a modification; male hind tibiae clearly recurved in the middle (Fig. 12), female hind tibiae straight.

Abdomen. Sterna without lateral submarginal furrow, ventral surface entirely punctured in female, but with lateral impunctate band on visible segments III and IV in male; lateral margins of each segment with a row of 5-6 setigerous punctures bearing long hair-like setae, and with well-developed posteriorly projecting spine. Sterna bearing erect light hairs, especially numerous close to lateral margins. Male genital capsule as in Fig. 17, paramere as in Figs 14-16. Female genital plates moderately broad (Fig. 18), densely punctate.

Material examined. SOUTH AUSTRALIA: 1 male, Sundews $n$. Hackham, in Malaise trap, 12 may 1975, M. Anderson (SAMA); WESTERN AUSTRALIA: 1 male, Yanchep $32 \mathrm{~km} \mathrm{~N}$ from Perth, 29.I-8.II 1936, R.E. Turner, B.M. 1936-28 (BMNH); 2 males 1 female, Rottnest, Lea, Pres. by Com. Inst. Ent., B.M. 1948-548 (BMNH); 1 female, Geraldton \& Mullewa, Lea, Pres. by Com. Inst. Ent. B.M. 1948-548 (BMNH); 1 female, Denmark, 34.57'S 117.21'E, January 1976, R.P. McMillan (WAMP); 1 female, Greenwood, Perth, 26. Jan. 1977, P.G. Kendrick (DBUO); 1 male, Fremantle, 91-82, 1870 (BMNH).

Distribution. New South Wales, South Australia (first record), Western Australia.

\section{Blaena coarctata Froeschner, 1960}

(Figs 19-27)

Blaena coarctata Froeschner, 1960: 457, 1966: 690; Lis, 1995: 138, 1996: 183.

\section{Redescription}

Body. Slender, almost parallel-sided (Fig. 19), length 5.02-5.55 (female), 5.10-5.85 (male).

Head (Fig. 20). Black or blackish brown, paraclypei coarsely punctured; lateral margins slightly narrowed anteriorly; paraclypei longer than clypeus and joined anteriorly; clypeus somewhat convex, bare; each paraclypeus with 6-9 long hair-like setae, among them 2-3 submarginal ones; bucculae bearing fine hairs; ocular index 2.83-3.29 (male), 3.09-3.47 (female); ocelli small, a distance between ocelli about 2.5-3.5 times longer than the distance between an ocellus and the eye, ocellar index 7.6-11.3; rostrum extending beyond anterior coxae, sometimes reaching base of middle coxae; length of antennal segments: I $0.21-0.29$, II $0.29-0.43$, III $0.50-0.74$, IV 0.69-1.13, V 0.83-1.03.

Prothorax. Pronotum about 1.2-1.4 times broader than long, black or blackish brown, coarsely punctured, conspicuously narrowed behind the middle (Fig. 21); dorsal surface of disc with a few scattered hairs; anterior margin broadly concave, middle of posterior margin concave; lateral margins entire, sometimes with very small tubercles at bases of setigerous punctures, each submargin with a row of 6-9 setigerous punctures bearing long hair-like setae (5-7 on anterior lobe, 1-2 on the posterior); transverse discal postmedial impression well-developed, broad. Prosternum black, punctured; prosternal carinae vague, bearing golden-brown woolly hairs. Propleuron black, shiny, coarsely punctured, its anterior margin with woolly hairs, lateral parts sparsely, shallowly punctured, bare.

Mesothorax. Scutellum (Fig. 19) black, shiny, slightly broader than long, punctation of disc a little more crowded than that of pronotum, median discal carina hardly visible; pilosity of scutellar disc very sparse, sometimes absent. Anterior part of mesopleuron coarsely punctured, evaporative area rounded, elongated, laterally narrowed and reaching lateral margin of mesopleuron. Corium brown, dark brown, or almost black, shiny, punctured with punctures larger than those of scutellum and pronotum (Fig. 19); costal margin without setigerous punctures bearing long hair-like setae, surface with scattered short hairs; membrane narrow, reaching the tip of abdomen (macropterous form), or shortened to intersegmental suture $6 / 7$ of abdomen (submacropterous form); veins dark, straight, not reticulate.

Metathorax. Metapleural evaporatorium, almost reaching lateral margin of metapleuron.

Legs. Anterior pair brown, shiny, bearing numerous erect light hairs; anterior tibiae apically broadened. Femora of middle pair with a row of small spines in both males and females; middle tibiae straight with black spines. Male hind femora with two rows of sharp spines ventrally (Fig. 22), female hind femora with very small tubercles ventrally; male hind tibiae clearly recurved basally and apically (Fig. 22), armed with strong spines and hairs; female hind tibiae straight, spines and hairs less numerous.

Abdomen. Sterna convex, dark brown, shiny, densely and uniformly punctured across entire width in females, males with a narrow impunctate and shiny strip laterally on III, IV and V sterna; lateral furrow shallow; posterior margin of surface IV and $\mathrm{V}$ with numerous well visible spines, lateral margins of each segment with 2-4 setigerous punctures bearing long hair-like setae, and with small posteriorly projecting spine. Male genital cap- 


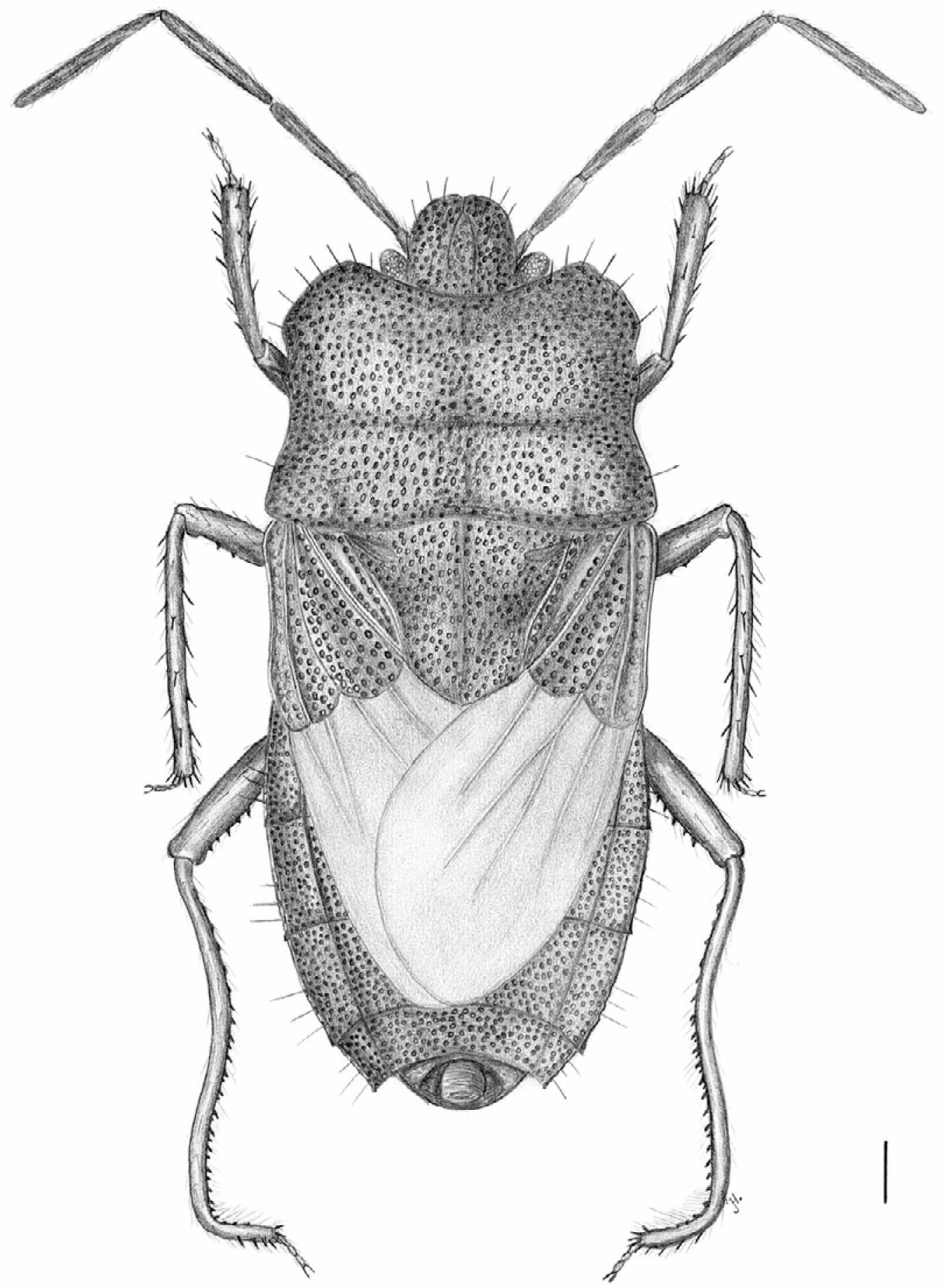

Fig. 19. Blaena coarctata Froeschner - dorsal view. Scale: $0.3 \mathrm{~mm}$.

sule as in Fig. 26, paramere as in Figs 23-25. Female genital plates narrow (Fig. 27), sparsely punctate.

Material examined. NEW SOUTH WALES: 1 male (paratype), Mulwala 1.6.53, F.E. Wilson, Blaena coarctata det. Froeschner (SAMA); 1 male, Tumutu R. 1956, J. Sedlacek (BPBM); QUEENSLAND: 1 male, C. Queensland, 22.02'S 118.03'E, Morananbuh, 6 km S. 5646, 25 Jun.-20 Dec. 1997, G.B. Monteith \& E. Kruck, flight intercept, box flat (QMBA); 1 male 1 female, S.W. Queensland, Morney Creek, $120 \mathrm{~km} \mathrm{W.} \mathrm{of}$ Windorah, 24 Sept. 1983, G.B. Monteith (QMBA, DBUO); 1 female, S.W. Queensland, $10 \mathrm{~km} \mathrm{~W}$ of Windorah, 23 Sept. 1983, G.B. Monteith (QMBA); 2 females, S.W. Queensland, 20 $\mathrm{km} \mathrm{E}$ of Thylunga, 22 Sept. 1983, G.B. Monteith (QMBA, DBUO); 1 female, W. Queensland, Stonehenge, 16 Oct. 1968, G.B. Monteith (UQIC); SOUTH AUSTRALIA: 1 male (paratype), 1 female (paratype), Woodforde Cr., Andamooka Rgs., 31 Aug. 1948, G.F. Gross, Blaena coarctata det. R.C. Froeschner (SAMA); 3 males, Gawler Ranges, Kolay Dam, 32.33'S 135.36'E, Paney Stn., pitfalls, 7-11 Dec. 1989, J. Forrest (SAMA, DBUO); VICTORIA: 1 female, Ultima, 8. 1915, comp. with type, Blaena coarctata det. R.C. Froeschner 61' (MVNH); 

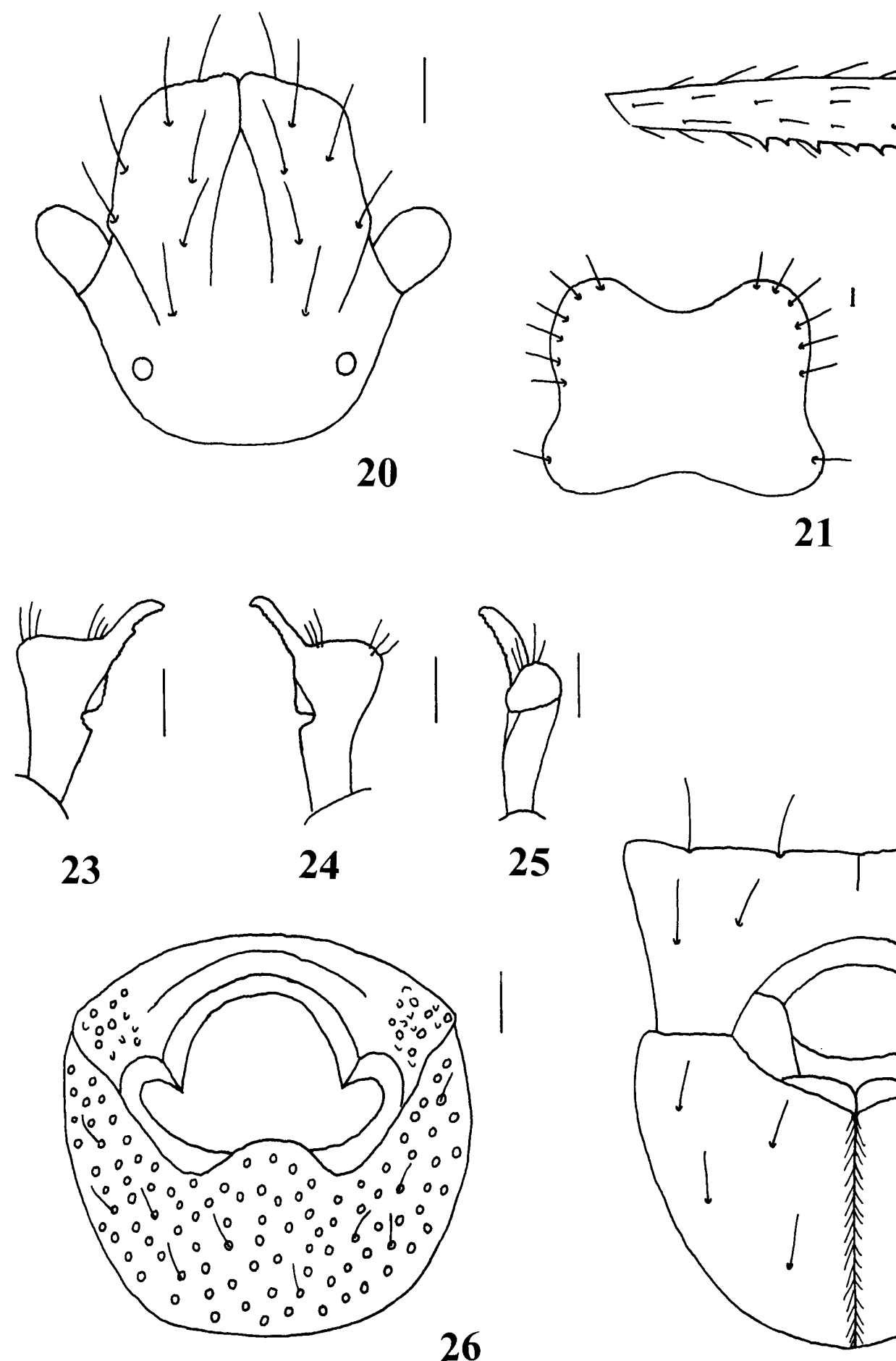

25

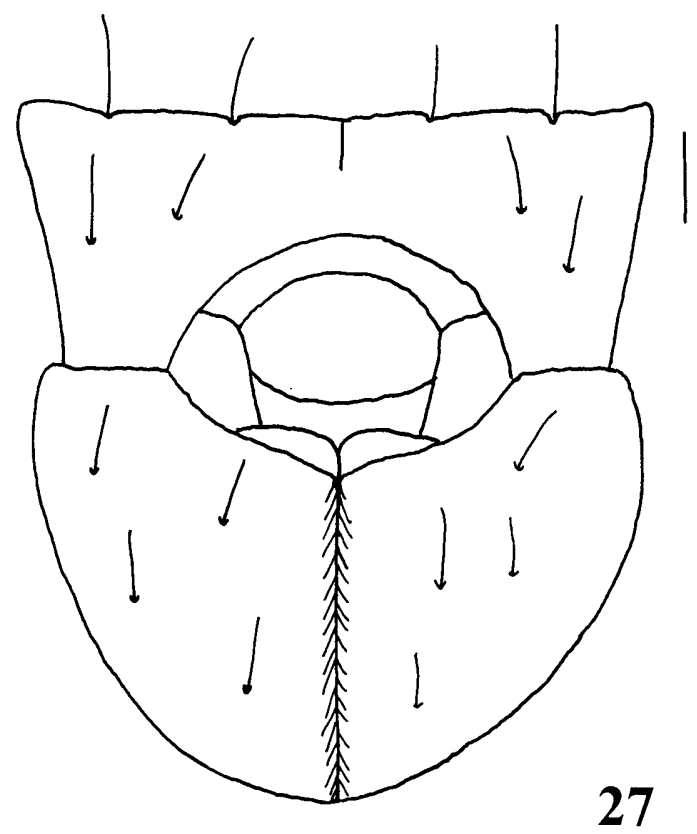

Figs 20-27. Blaena coarctata Froeschner. 20 - head; 21 - pronotum; 22 - male hind leg; 23-25 - various views of paramere; 26 male genital capsule; 27 - female genital plates. Scale: $0.1 \mathrm{~mm}$.

WESTERN AUSTRALIA: 3 males 3 females, Tallering Stn., 1.IX.1976, R.P. McMillan, under rock (WAMP, DBUO).

Distribution. New South Wales, Queensland (first record), South Australia, Victoria, Western Australia (first record).

\section{Blaena hirta sp. $\mathbf{n}$.}

(Figs 28-32)

\section{Description}

Body. Length 3.55-4.20 (females only - Figs 28-29).

Head (Fig. 30). Black, paraclypei coarsely punctured and bearing short, semi-erect golden brown woolly hairs; lateral margins narrowed anteriorly; paraclypei longer than clypeus and joined anteriorly; the latter convex, finely pilose; each paraclypeus with 5 long hair-like setae, 


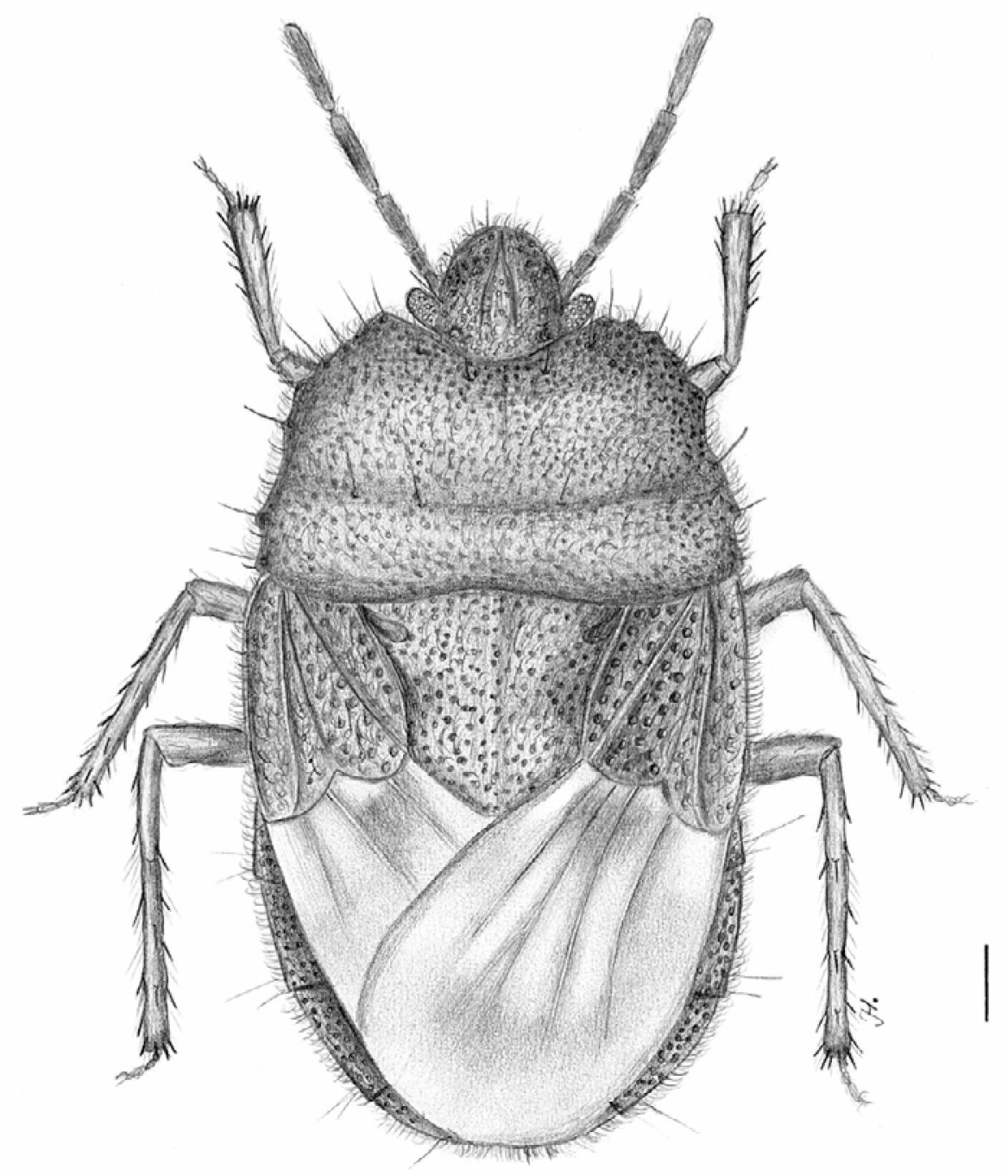

Fig. 28. Blaena hirta sp. n., macropterous form - dorsal view. Scale: $0.3 \mathrm{~mm}$.

among them 3 submarginal ones; bucculae finely pilose; ocular index 3.00-3.73 (females only); ocelli small, distance between ocelli about 2.2-2.8 times greater than the distance between an ocellus and the eye, ocellar index 6.5-12.0; rostrum extending beyond anterior coxae, almost reaching middle coxae; length of antennal segments: I $0.15-0.22$, II $0.11-0.13$, III $0.40-0.41$, IV $0.36-0.63$, V $0.43-0.66$.

Prothorax. Pronotum (Figs 28, 29, 31) about 1.7-1.9 times broader than long, black, coarsely punctured; dorsal surface of disc with short woolly hairs; anterior margin broadly concave, posterior margin almost straight, only slightly concave in the middle; lateral margins conspicuously serrated, each submargin with a row of 8-10 long hair-like setae; transverse discal postmedial impression shallow. Prosternum black, punctured; prosternal carinae well developed, short golden-brown woolly hairs. Propleuron black, shiny, coarsely punctured, its anterior margin with woolly hairs, lateral parts shallowly punctured, bearing numerous hairs.
Mesothorax. Scutellum (Fig. 28, 29) black, slightly broader than long, punctation of disc same as that of pronotum, median discal carina more or less visible; scutellar disc bearing woolly hairs over its entire surface. Anterior part of mesopleuron coarsely punctured, evaporative area rounded, elongated, reaching lateral margin of mesopleuron. Corium black, blackish brown or dark brown, punctures somewhat larger than those of scutellum and pronotum, and with numerous woolly hairs; costal margin without setigerous punctures bearing long hair-like setae, its surface only with numerous woolly hairs; membrane brown, semihyaline, with pale patches basally, reaching the tip of abdomen (macropterous form - Fig. 28), or shortened, almost reaching the intersegmental suture $4 / 5$ or $5 / 6$ of abdomen (brachypterous form - Fig. 29); veins dark brown, straight, not reticulate.

Metathorax. Metapleural evaporatorium large, almost reaching lateral margins of metapleuron. 


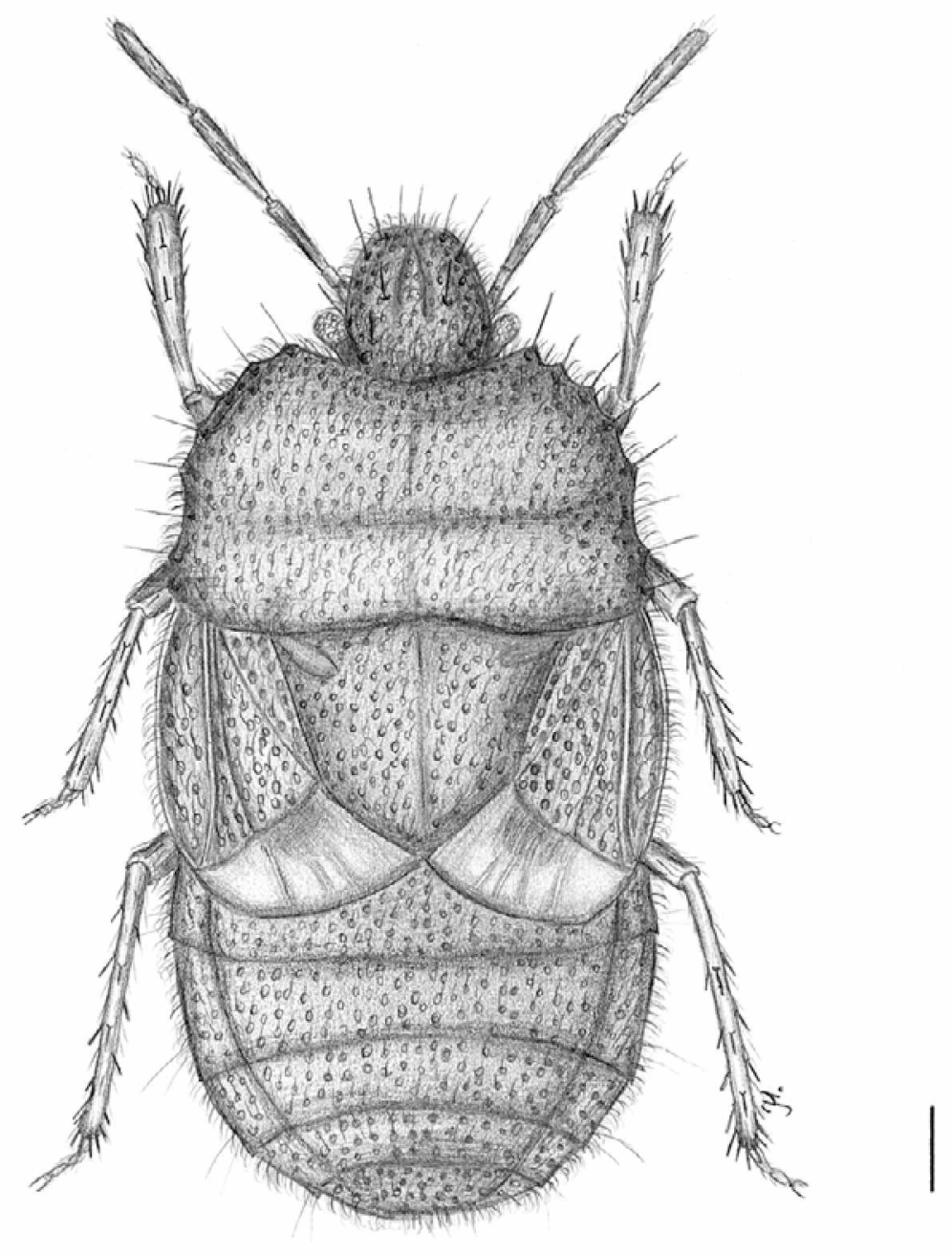

Fig. 29. Blaena hirta sp. n., brachypterous form - dorsal view. Scale: $0.3 \mathrm{~mm}$.

Legs. Not specifically modified; femora dark brown with pale hairs; tibiae straight, armed with a few black spines.

Abdomen. Sterna convex, black, coarsely punctured; surface of sterna with numerous short semi-erect hairs, lateral margins of each segment without or with a single setigerous puncture bearing a long hair-like seta, and with a very small posteriorly projecting spine. Female genital plates narrow (Fig. 32), bearing numerous golden brown short hairs.

Material examined. Holotype (macropterous female) and 4 paratypes (2 macropterous and 2 brachypterous females): QUEENSLAND: 1 female (holotype), Queensland, Mt. Coottha, Brisbane, 1.viii.1966, R.A. Crowson (UQIC); 1 female, Queensland, Mt. Coot-tha, Brisbane, 1.viii.1966, R.A. Crowson (UQIC); 2 females, Queensland, Mt. Coot-tha, Brisbane, R.A Crowson, ex litter (UQIC, DBUO); 1 female, Queensland, Forest Station, 2000' Bulburin State Forest, via Many Peaks, 2-5.IV.1972, G.B. Monteith (UQIC).

Etymology. The species name refers to its dense body pilosity.

\section{Comparative notes}

This new species is characterized by the following characters: clypeus convex; each paraclypeus with 5 long hair-like setae, among them 3 submarginal ones; second antennal segment minute, shorter than both the 1st and the 3rd; prosternal carinae well developed, bearing golden-brown woolly hairs; lateral margins of pronotum serrated, each submarginally with a row of $8-10$ long hair-like setae; costal margin without setigerous punctures bearing long hair-like setae.

Brachypterous females are similar to $B$. tamasi, the only other species with distinctly shortened wings, but the latter has staphylinoid like wings (hemelytra reaching to intersegmental suture $3 / 4$ of abdomen). Moreover, both species can easily be separated on the basis of the number of submarginal setigerous punctures on head and pronotal margins (3 and 8-10 respectively in $B$. hirta, 1 and 5-6 respectively in $B$. tamasi).

Macropterous females are similar to those of $B$. serrata, but differs in having minute second antennal segments, as 

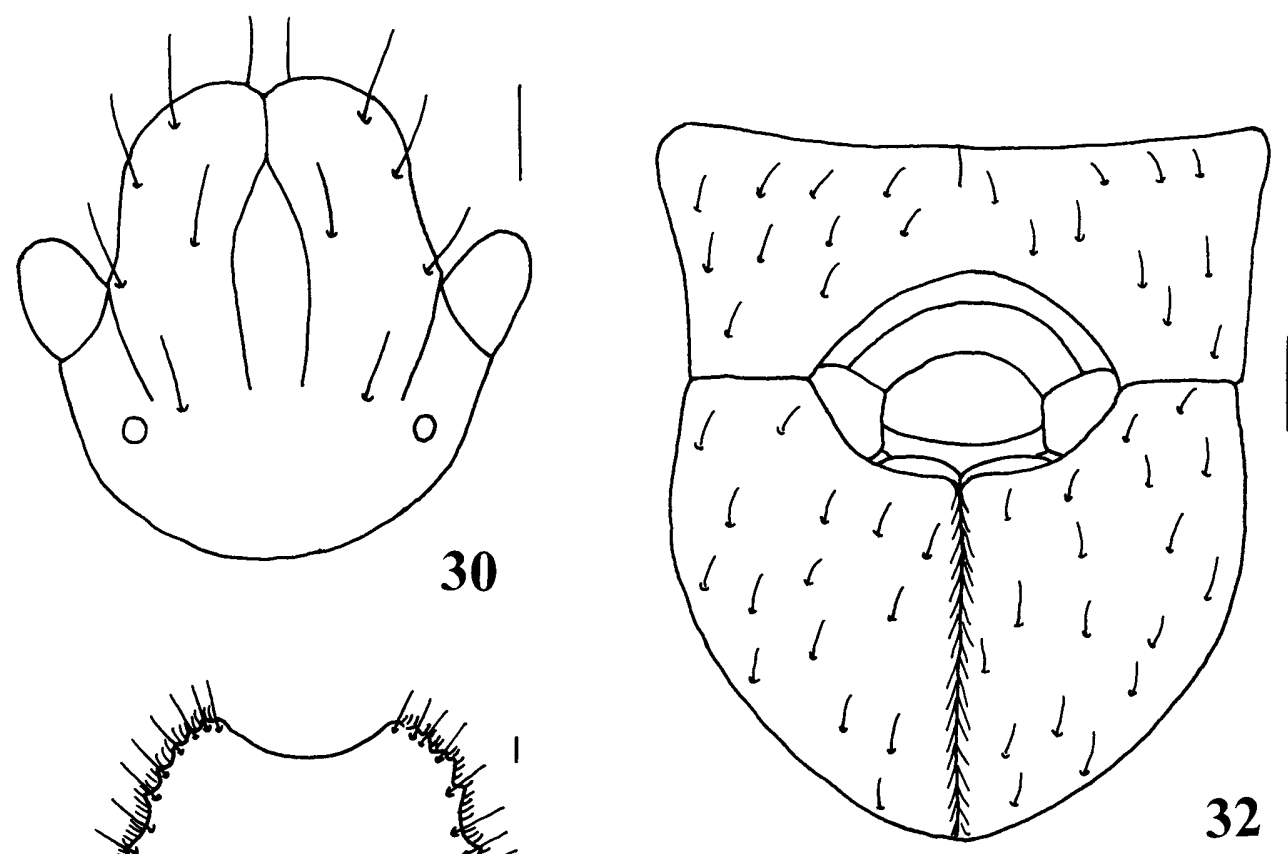

31

Figs 30-32. Blaena hirta sp. n. 30 - head; 31 - pronotum; 32 - female genital plates. Scale: $0.1 \mathrm{~mm}$.

well as a dense pilosity on head, pronotum, scutellum and abdomen.

Distribution. Queensland.

\section{Blaena mediocarinata Froeschner, 1960}

(Figs 33-40)

Blaena mediocarinata Froeschner, 1960: 459; Lis, 1995: 139, 1996: 183.

\section{Redescription}

Body. Length 5.15-5.40 (female), 4.70-5.20 (male Fig. 33).

Head (Fig. 34). Black, shiny, paraclypei coarsely punctured, forming a ridge paralleling clypeus on either side; lateral margins almost parallel in front of eyes; paraclypei longer than clypeus and joined anteriorly, but its apex usually visible in dorsal view; the latter strongly convex; each paraclypeus with four setigerous punctures bearing long hair-like setae, among them a single preocular; bucculae somewhat narrowed posteriorly; eyes castaneous, ocular index 3.80-4.60 (male), 4.21-4.71 (female); ocelli small, a distance between ocelli about 3.6-4.2 times greater than the distance between an ocellus and the eye, ocellar index 6.3-9.6; rostrum extends beyond middle coxae, and almost reaches the posterior coxae; length of antennal segments: I $0.22-0.25$, II $0.15-0.19$, III 0.54-0.63, IV 0.59-0.64, V 0.69-0.78.

Prothorax. Pronotum about 1.5-1.7 times broader than long (Fig. 35), black, shiny, coarsely punctured, laterally conspicuously explanate (Fig. 33); dorsal surface of disc with four long hairs close to anterior margin and four in the postmedial impression; anterior margin broadly concave, posterior margin almost straight; lateral margins with a strong prebasal angular projection; each submargin with a single setigerous puncture bearing long hair-like seta on anterior lobe, and a single setigerous puncture on the prebasal projection of posterior lobe (Fig. 35); transverse postmedial impression deep and well-developed, abruptly interrupted by carinate midline (Fig. 33). Prosternum black, punctured; prosternal carinae welldeveloped, high, bearing a few short hairs. Propleuron black, coarsely punctured, its anterior margin bare, lateral parts shallowly punctured, bare.

Mesothorax. Scutellum blackish brown, shiny, slightly wider than long, punctation on disc almost as dense as on pronotum, scutellar apex sparsely punctured, median discal carina prominently developed, except for its extreme apical part (Fig. 33); scutellar disc bare, its lateral parts with deep impressions and strongly elevated tuberosities anteriorly. Anterior part of mesopleuron punctured, shiny; evaporative area rounded, elongated and reaching lateral margin. Corium dark brown to black, shiny, coarsely punctured, costal margin without setigerous punctures bearing long hair-like setae; membrane semihyaline, normally developed, reaching or almost reaching the tip of abdomen, veins irregularly branched, sometimes reticulate; base of membrane with pale spots. 


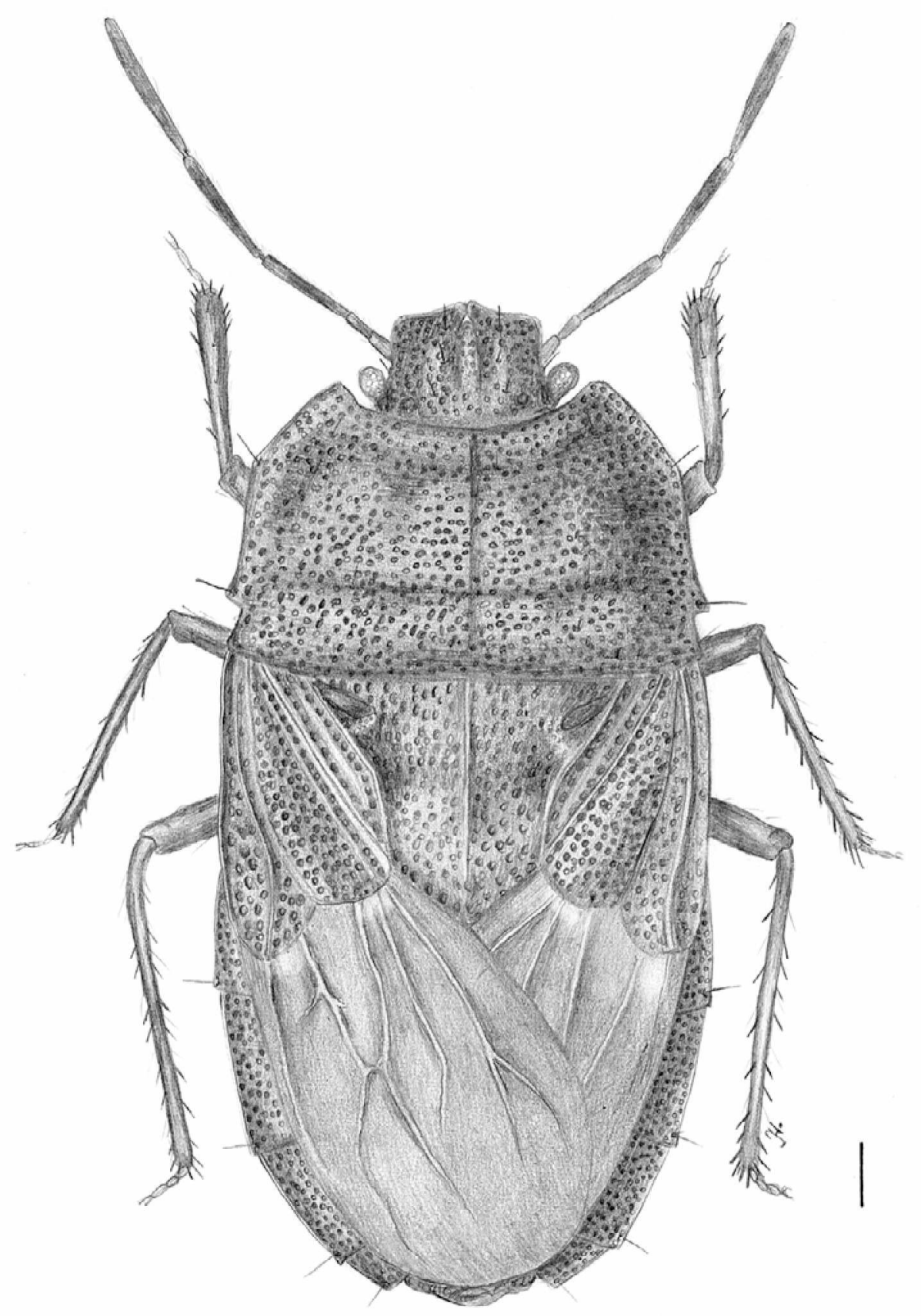

Fig. 33. Blaena mediocarinata Froeschner - dorsal view. Scale: $0.3 \mathrm{~mm}$.

Metathorax. Metapleural evaporatorium large, almost reaching lateral margin of metapleuron, peritreme strongly elongated.

Legs. Femora dark brown, finely pilose, without spines; tibiae straight, brown, bearing short black fine spines; male posterior tibiae not specifically modified.

Abdomen. Sterna convex, blackish brown, shiny, punctation dense and coarse, except lateral impunctate bands on segments IV and V in males; lateral margins of each segment with a single setigerous puncture bearing long hair-like seta, and a weakly posteriorly projecting lobe. Sterna almost bare, with few erect hairs. Male genital capsule as in Fig. 40, paramere as in Figs 37-39. Female genital plates broad (Fig. 36), sparsely punctate.

Material examined. SOUTH AUSTRALIA: 2 males 1 female, Gum Lagoon, 36.17'S 140.02'E, pitfall, 24-26 March 1992, E.G. Matthews, Jafforest (SAMA, DBUO); 1 male 1 female, 90 mile desert, Comet Bare Heath Litter, 10 Oct. 1977, P.J.M. Greenslade (SAMA); 2 females, Muston K.I., Pelican Lagoon, 30 Sept. 1966, H.M. Cooper (SAMA, DBUO). 

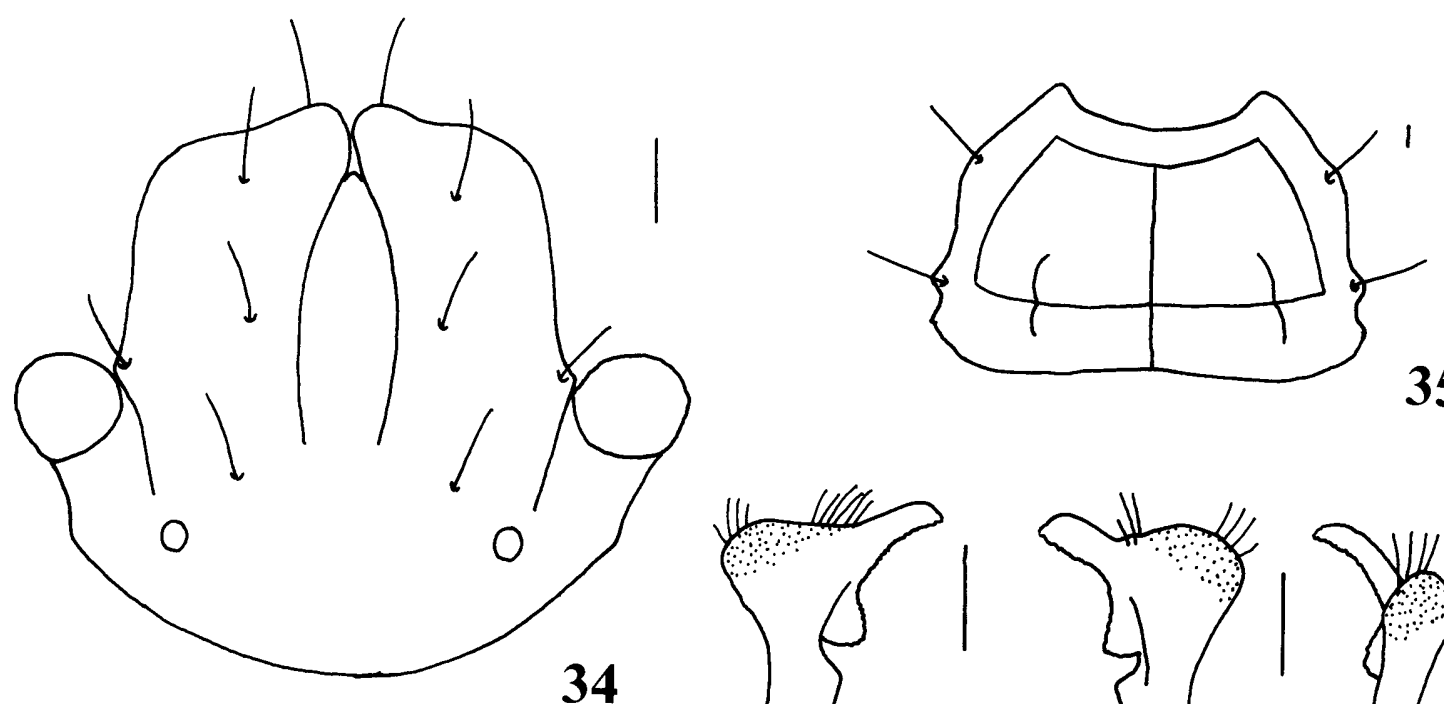

35

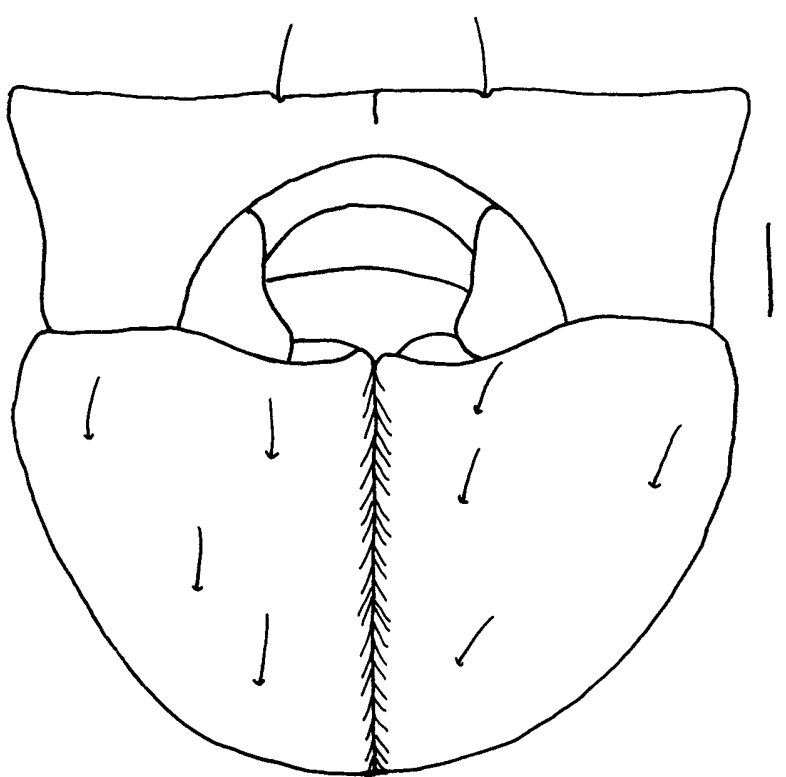

36

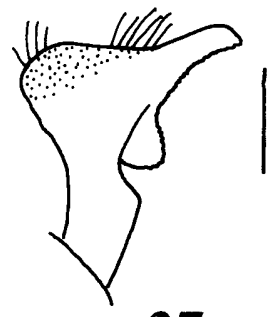

37

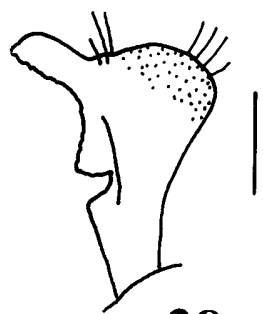

38
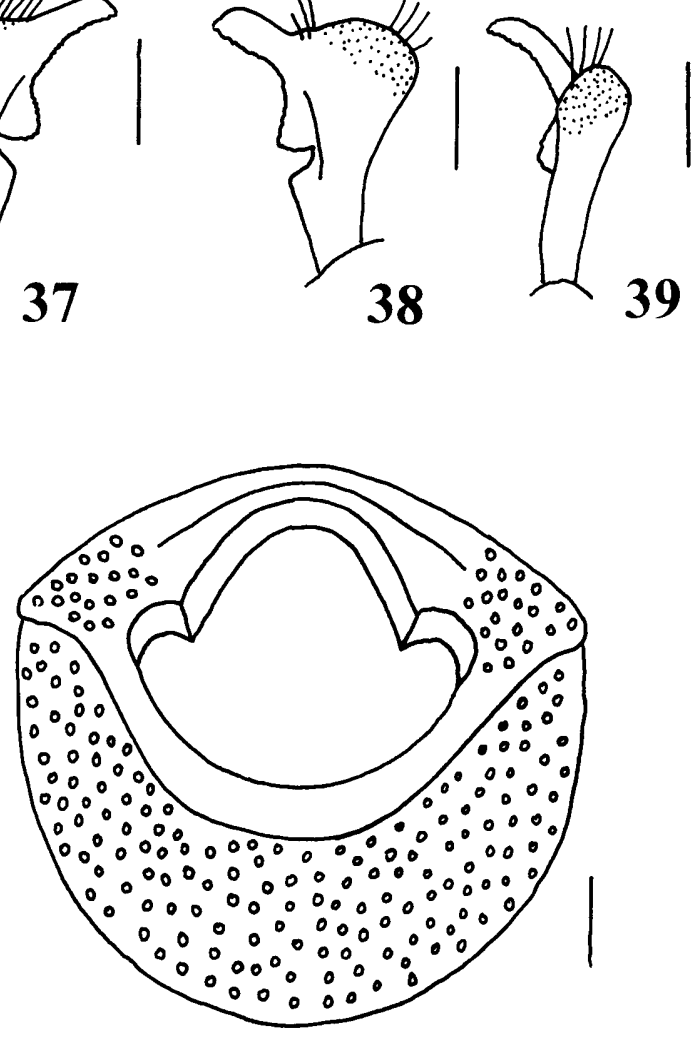

40

Figs 34-40. Blaena mediocarinata Froeschner. 34 - head; 35 - pronotum; 36 - female genital plates; 37-39 - various views of paramere; 40 - male genital capsule. Scale: $0.1 \mathrm{~mm}$. lia.

Distribution. South Australia (first record), Western Austra-

\section{Blaena multitricha Froeschner, 1960}

(Figs 41-48)

Blaena multitricha Froeschner, 1960: 460; Lis, 1995: 139, 1996: 185.

\section{Redescription}

Body. Length 4.70-5.84 (female), 5.44-5.50 (male).

Head (Fig. 43). Black, shiny, punctured, bearing numerous long hair-like setae, including 4-6 submarginal setae; lateral margins narrowing anteriorly, almost parallel-sided anterior to eyes; paraclypei longer than clypeus and joined anteriorly; the latter long, somewhat convex, bare; bucculae with fine hairs; ocular index
2.95-3.74 (female), 2.52-3.17 (male); ocelli small, distance between ocelli about 3.5-4.2 times greater than distance between an ocellus and the eye, ocellar index 9.3-15.4; rostrum extending beyond anterior coxae; length of antennal segments: I $0.24-0.25$, II $0.31-0.34$, III 0.43-0.48, IV 0.64-0.69, V 0.65-0.79.

Prothorax. Pronotum blackish brown or black, shiny, coarsely punctured, about 1.5-1.9 times broader than long (Fig. 42); its dorsal surface with scattered long hairs; anterior margin deeply concave, posterior margin concave centrally; lateral margins not serrated, each submargin with a row of 16-20 setigerous punctures bearing long hair-like setae; transverse postmedial impression shallow. Prosternum black, punctured; prosternal carinae welldeveloped, bare or finely pilose with a few light short 

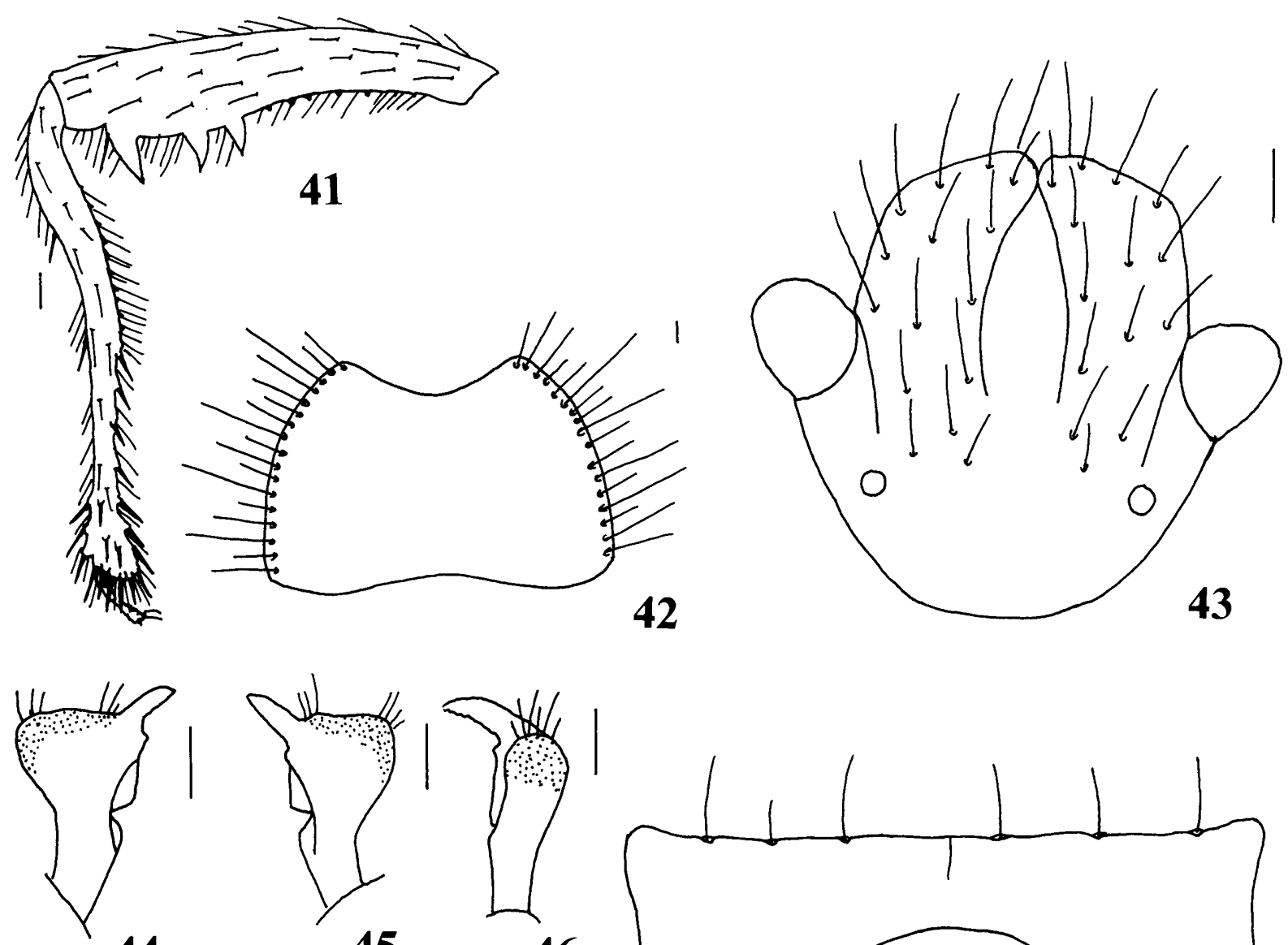

44

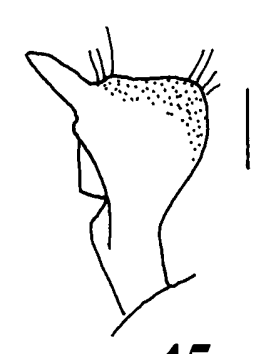

45
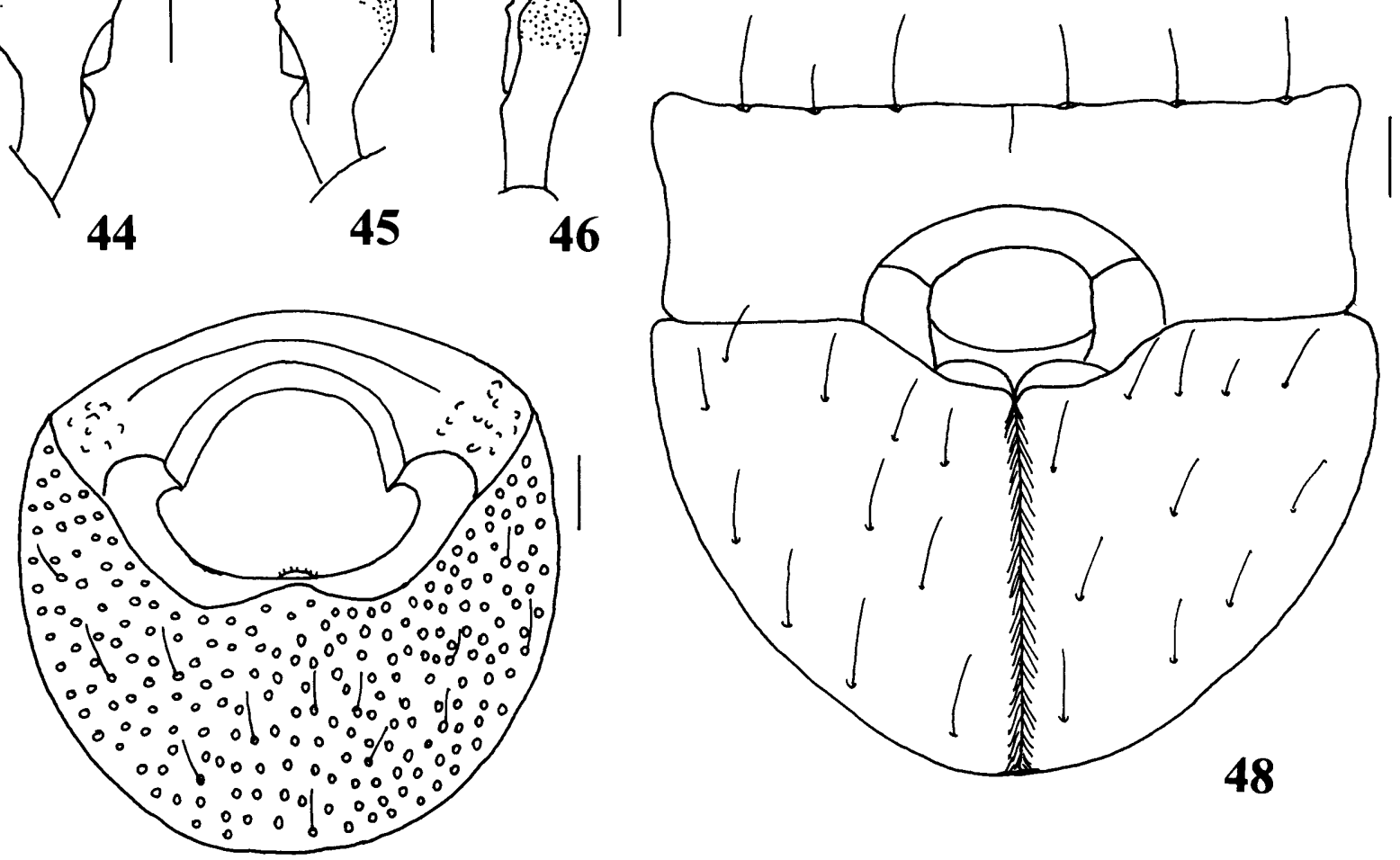

47

Figs 41-48. Blaena multitricha Froeschner. 41 - male hind leg; 42 - pronotum; 43 - head; 44-46 - various views of paramere; 47 male genital capsule; 48 - female genital plates. Scale: $0.1 \mathrm{~mm}$.

hairs. Propleuron black, shiny, coarsely punctured, its anterior margin finely pilose, lateral parts shallowly punctured, bare.

Mesothorax. Scutellum black or blackish brown, slightly wider than long, punctation of disc as dense as that of pronotum, median discal carina narrow, more or less visible; scutellar disc with numerous scattered long hairs of different length. Anterior part of mesopleuron punctured, evaporative area narrow, reaching lateral margins. Corium from dark brown to black, punctured, bearing well visible scattered hairs of different length; costal margin with 6-15 setigerous punctures bearing long hair-like setae; membrane normally developed, narrower than abdomen, reaching or almost reaching its tip, 
veins branched and reticulate, darker than the remaining surface of membrane.

Metathorax. Metapleural evaporatorium narrow, not reaching lateral margin of metapleuron, peritreme elongated.

Legs. Anterior femora brown, shiny, bearing small dark tubercles on underside; anterior tibiae, moderately broadened apically and bearing black spines. Femora of middle pair with a row of small tubercles ventrally; middle tibiae straight with black spines. Male hind femora ventrally with 3-4 strong spines (Fig. 41); female hind femora ventrally with a row of small blunt spines; male hind tibiae bowed, thickened medially and apically (Fig. 41), female hind tibiae straight; all tibiae with short black spines and numerous short erect hairs.

Abdomen. Sterna black or dark brown, shallowly impressed sublaterally, entirely coarsely punctured in females, males with lateral margins of segment IV and antero-lateral angles of segments III and V impunctate; lateral margins of each segment with a row of 3-5 setigerous punctures, and with at least one welldeveloped posteriorly projecting spine, sometimes more small spines are present along entire lateral margin of each segment. Sterna with numerous golden brown hairs of different length. Male genital capsule as in Fig. 47, paramere as in Figs 44-46. Female genital plates broad (Fig. 48), densely punctate.

Material examined. NORTHERN TERRITORY: 1 male 1 female, Yuendumu, Feb'68, G. Watts (SAMA); 1 male, The Pines, Nr. Arcoona Station (SAMA); SOUTH AUSTRALIA: 1 female (paratype), Woodforde Ck., Andamooka Rgs. 31 Aug. 1948, G.F. Gross, Blaena multitricha det. R.C. Froeschner (SAMA); 1 female, S. Australia, coll. Nickerl, Mus. Pragaensis (NMPC); QUEENSLAND: 1 female (paratype), Queensland, Cunnamulla, H. Hardcastle, Blaena multitricha det. R.C. Froeschner (SAMA); 1 female, NE Queensland, Marsupial Ck., via Croydon. pitfalls, March 96-March 1997, J. \& P. Hasenpush (QMBA); WESTERN AUSTRALIA: 1 male, MeekatharraBilliluna Pool, Canning Stock, Rte Exp, Apr.1930-Aug.1931 (SAMA).

Distribution. Northern Territory (first record), South Australia, Queensland, Western Australia (first record)

\section{Blaena parathroposa sp. $\mathrm{n}$.}

(Figs 49-57)

\section{Description}

Body. Length 5.20 (holotype male only - Fig. 49).

Head (Fig. 50 - left paraclypeus somewhat damaged). Black, shiny, punctured and bearing numerous long hairlike setae; lateral margins almost parallel-sided anterior to the eyes; paraclypei longer than clypeus, the latter convex; each paraclypeus with a submarginal row of 6 long hair-like setae; bucculae sparsely and finely pilose; ocular index 2.86; ocelli small, distance between ocelli about 2.30 times greater than the distance between an ocellus and the eye, ocellar index about 12.0; rostrum extending beyond anterior coxae; length of antennal segments: I 0.27 , II 0.32 , III 0.52 , IV 0.76 , V 0.78 .
Prothorax. Pronotum black, shiny, coarsely punctured, about 1.5 times broader than long (Fig. 51); its dorsal surface with erect golden hairs; anterior margin broadly concave, posterior margin concave centrally; lateral margins not serrated, almost parallel, each submargin with a row of 20-21 long hair-like setae; transverse postmedial impression broad and shallow. Prosternum black, punctured; prosternal carinae well-developed, high, bearing short, woolly hairs. Propleuron black, shiny, coarsely punctured, its anterior margin with woolly hairs, lateral parts shallowly punctured.

Mesothorax. Scutellum black, slightly wider than long, punctation of disc coarse, median discal carina well visible along its entire length (Fig. 49); pilosity of scutellar disc scattered. Anterior part of mesopleuron punctured, evaporative area narrowed laterally and almost reaching lateral margin of mesopleuron (Fig. 57). Corium dark brown, costal margin with 10-11 setigerous punctures bearing long hair-like setae; membrane normally developed, brown with pale basal spot, veins branched, darker than the remaining surface of membrane.

Metathorax. Metapleural evaporatorium moderately large, almost reaching lateral margin of metapleuron (Fig. 57), peritreme elongated.

Legs. Anterior femora dark brown, slightly shiny, bearing numerous erect light hairs and a few short spines; anterior tibiae broadened apically. Femora of middle pair with a few thin spines on the anterior margin of ventral side and a row of small spines on its posterior margin; tibiae straight with black spines. Hind femora ventrally with a row of short spines (Fig. 52); hind tibiae characteristically curved (Fig. 52), bearing numerous short black spines on inner margin.

Abdomen. Sterna black, shiny, not impressed sublaterally, entirely coarsely punctured, except for lateral impunctate band on visible segment IV, and partly on III and $\mathrm{V}$; posterior margin of sterna $\mathrm{V}$ and VI with large long spines; lateral margins of each segment with a row of 6 setigerous punctures, and with well-developed posteriorly projecting spine. Male genital capsule as in Fig. 56, paramere as in Figs 53-55.

Material examined. Holotype male: QUEENSLAND: CQ, 23o55'S x 151o20'E, Boyne Island, via Gladstone, 5022, 1995 C.Q. University, QMT 93013 (QMBA).

Etymology. The species name refers to its close affinity to $B$. blothroposa.

\section{Comparative notes}

The new species is characterized by the following characters: clypeus convex; each paraclypeus with 6 submarginal long hair-like setae; second antennal segment longer than the 1st; prosternal carinae well-developed, bearing woolly hairs; lateral margins of pronotum not serrated, submarginally with a row of 20-21 long hair-like setae; costal margin with a row of 10-11 setigerous punctures bearing long hair-like setae; hind male tibiae strongly recurved.

Male of the new species is similar in general habitus to B. blothroposa, but it is easily distinguished from the 


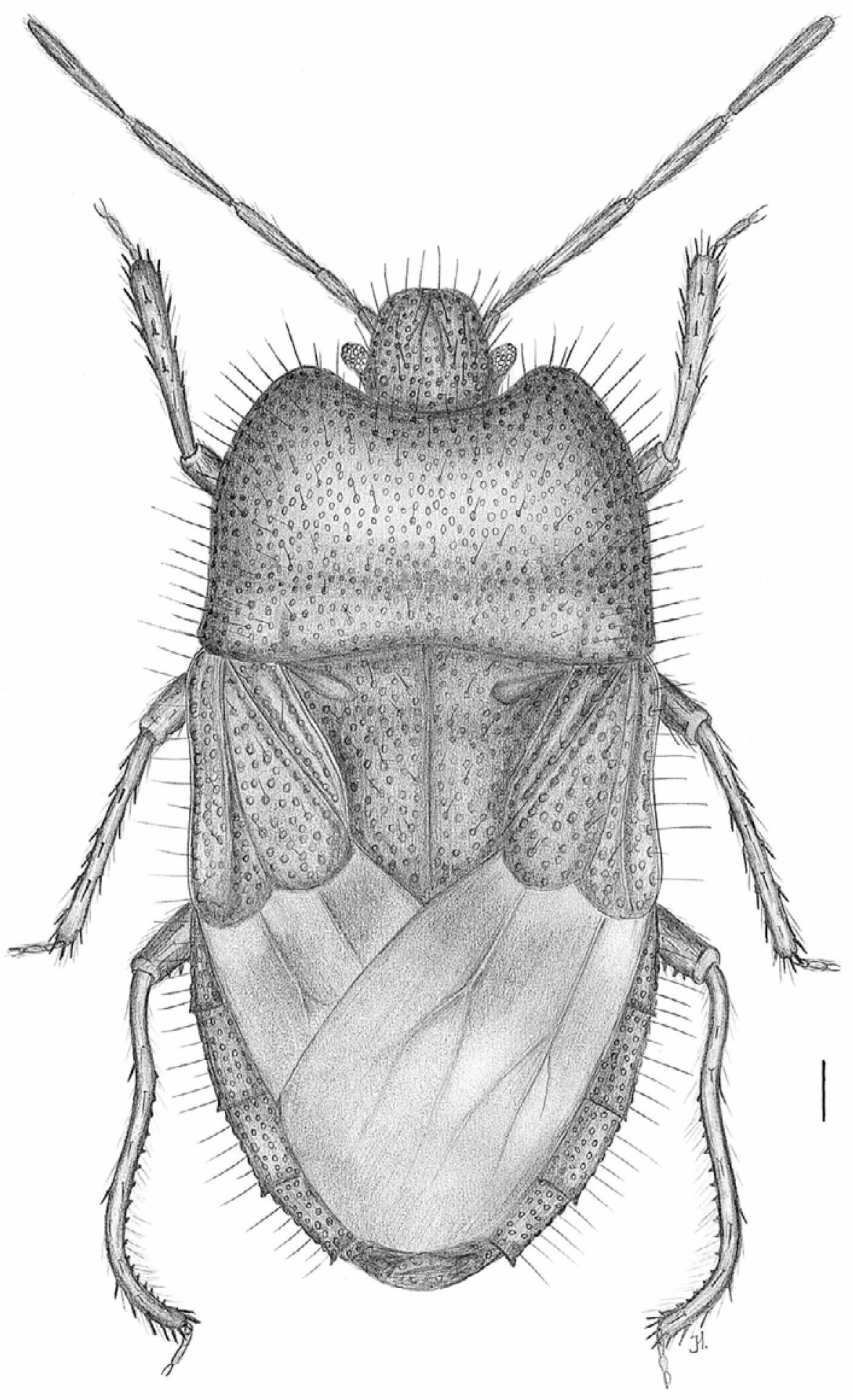

Fig. 49. Blaena parathroposa sp. n. - dorsal view. Scale: $0.3 \mathrm{~mm}$.

latter by its better developed and densely pilose prosternal carinae, the number of setigerous punctures bearing long hair-like setae on lateral body margins (B. parathroposa: pronotum 20-21, costal margin 10-11; B. blothroposa: pronotum 15, costal margin 7-9). Moreover, both species differ in the edentation on the male hind femora (ventral margin with a row of small tubercle-like spines in $B$. parathroposa, with a row of strong large spines in $B$. blothroposa), as well as in the ocular and ocellar indices (B. parathroposa -2.86 and 12.0 , respectively; $B$. blothroposa $-3.50-3.70$ and 8.0-11.0, respectively).

Distribution. Queensland. 

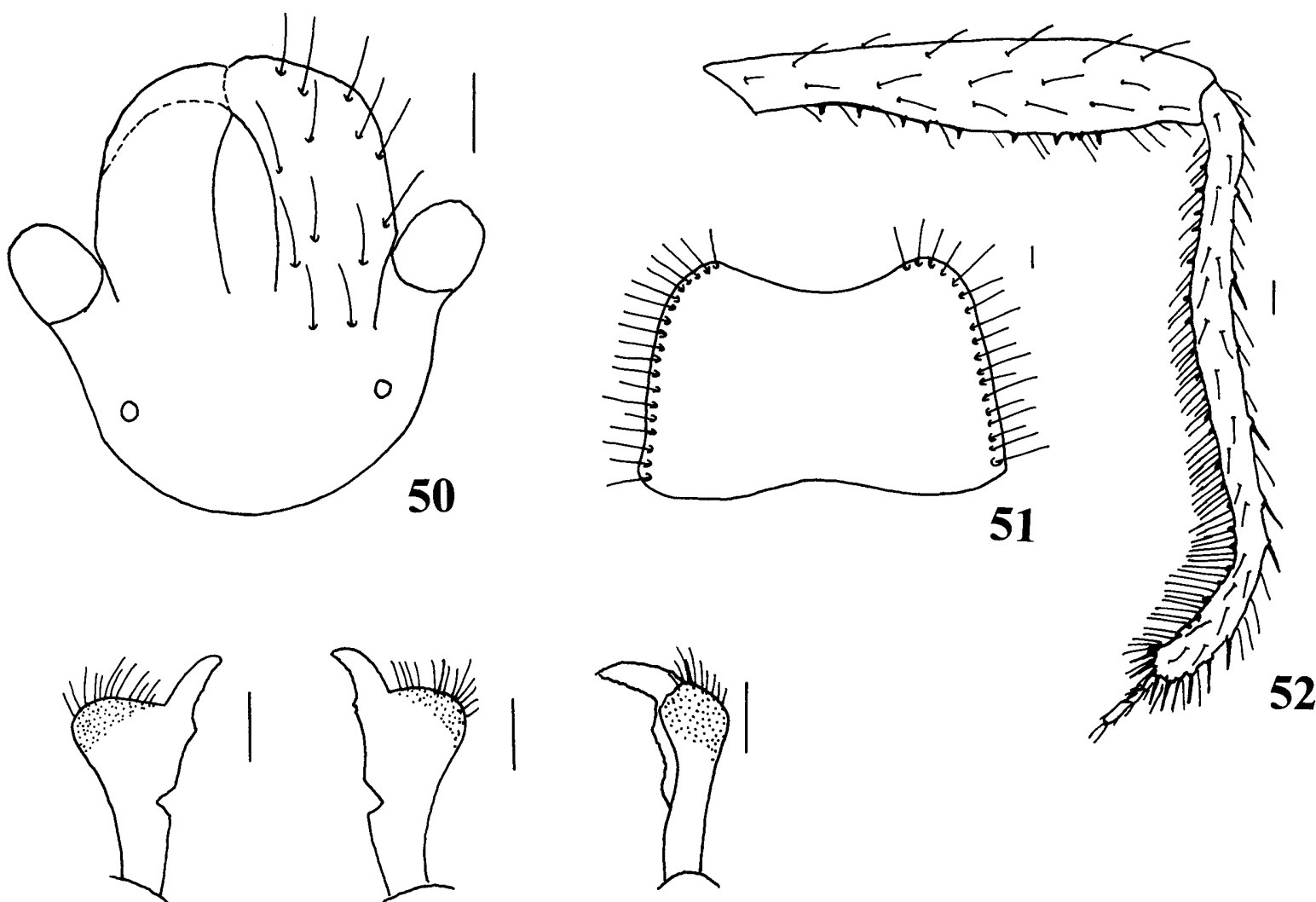

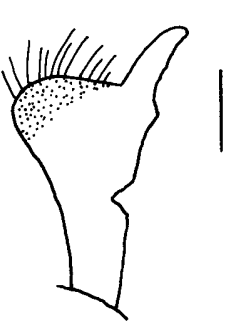

53

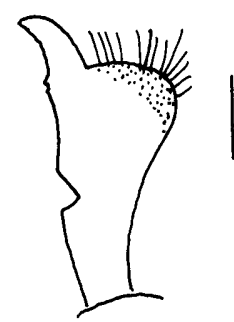

54

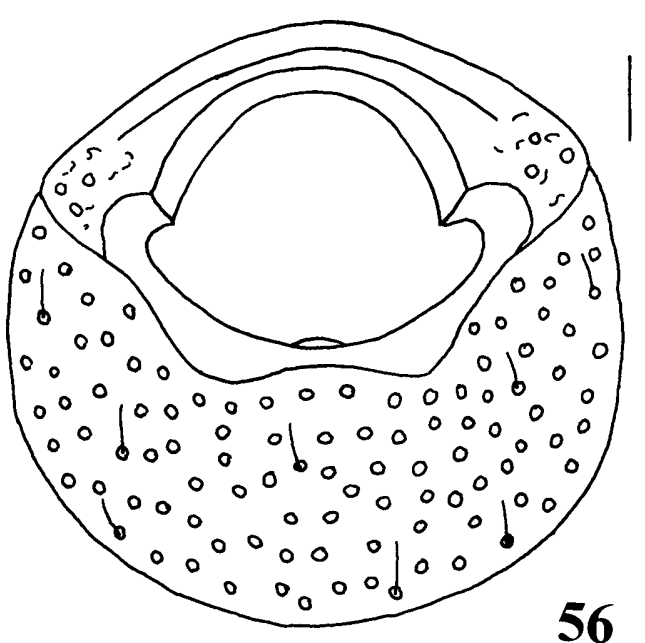

55

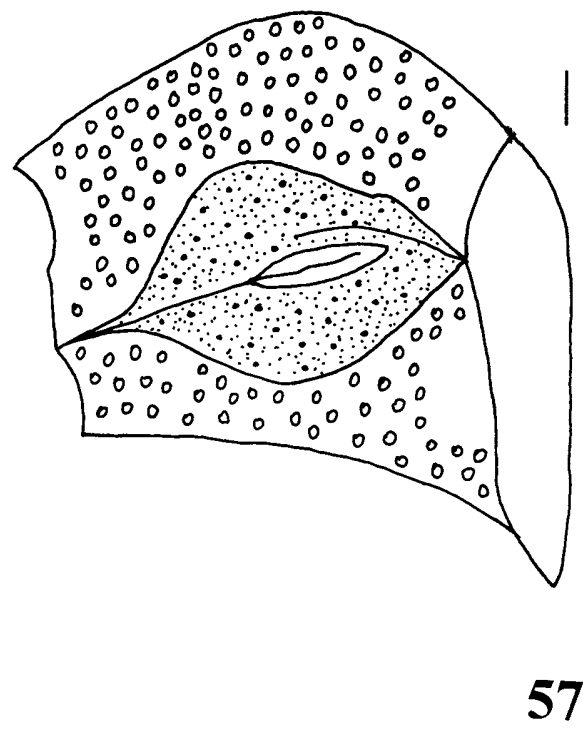

Figs 50-57. Blaena parathroposa sp. n. 50 - head; 51 - pronotum; 52 - male hind leg; $53-55$ - various views of paramere; 56 male genital capsule; 57 - evaporatoria on meso- and metapleuron. Scale: $0.1 \mathrm{~mm}$.

\section{Blaena pseudosetosa sp. n.}

(Figs 58-67)

\section{Description}

Body. Length 5.15 (holotype male only - Fig. 58).

Head (Fig. 59). Black, shiny, punctured and bearing numerous long hairs; lateral margins almost parallel-sided anterior to eyes; paraclypei longer than clypeus, the latter slightly convex; each paraclypeus with a submarginal row of 5-6 long hair-like setae; bucculae sparsely finely pilose; ocular index 3.57; ocelli small, distance between ocelli about 2.60 times greater than the distance between an ocellus and an eye, ocellar index about 8.2 ; rostrum extending beyond anterior coxae; length of antennal segments: I 0.27 , II 0.29 , III 0.41 , IV 0.48 , V 0.46 .

Prothorax. Pronotum black, shiny, coarsely punctured, about 1.5 times broader than long (Fig. 62), lateral margins dark castaneous; its dorsal surface with scattered long hairs; anterior margin deeply broadly concave, posterior margin slightly concave centrally; lateral margins 


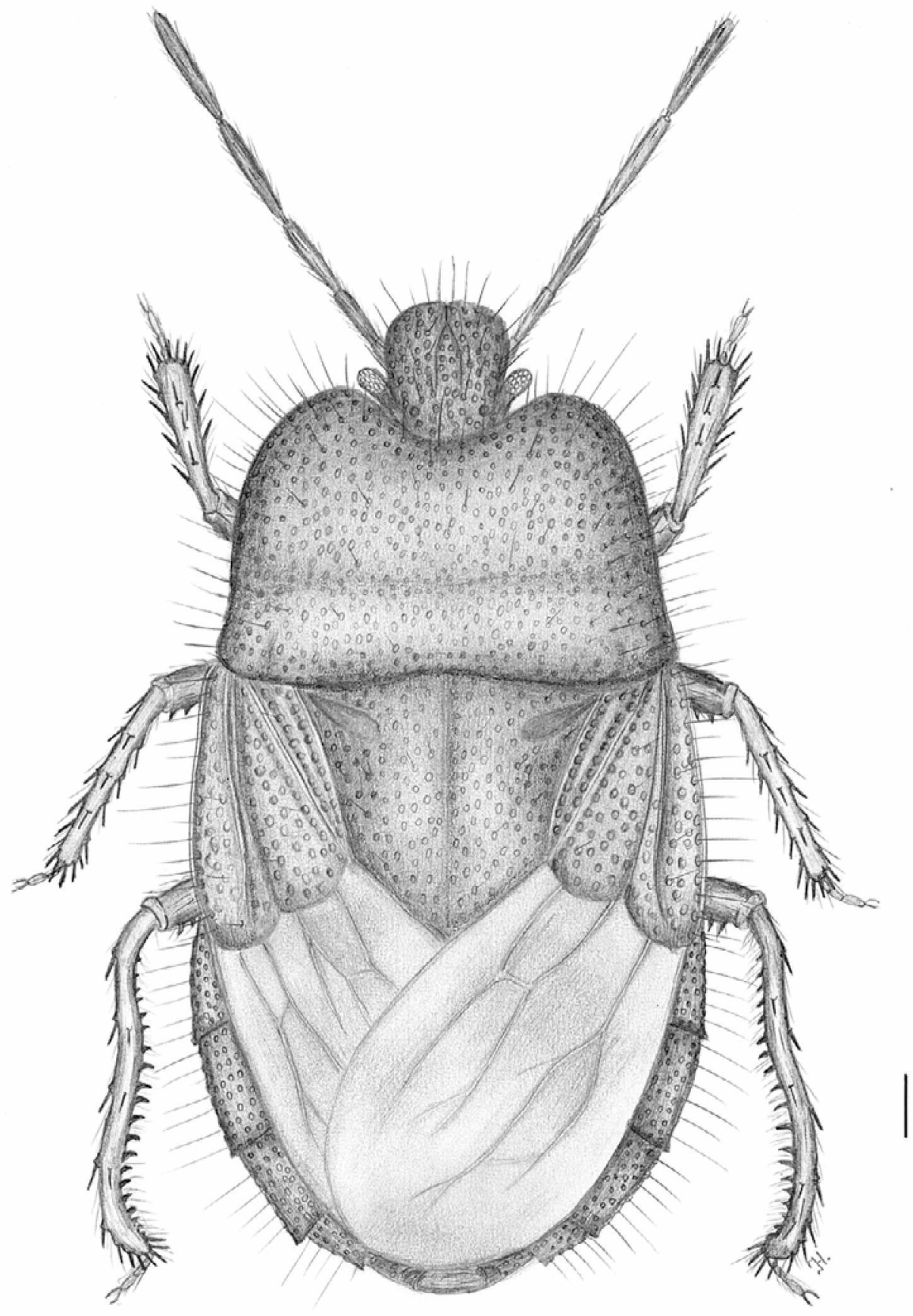

Fig. 58. Blaena pseudosetosa sp. n. - dorsal view. Scale: $0.3 \mathrm{~mm}$.

not serrated, each submargin with a row of 21-23 long hair-like setae; transverse postmedial impression broad and shallow. Prosternum black, punctured; prosternal carinae vague, low, pilosity hardly visible. Propleuron black, shiny, coarsely punctured, its anterior margin with woolly hairs, lateral parts with single shallow punctures.

Mesothorax. Scutellum black, wider than long, punctation of disc coarse, median discal carina vague; pilosity of scutellar disc scattered. Anterior part of mesopleuron punctured, evaporative area narrow, laterally reaching margin of mesopleuron (Fig. 63). Corium dark brown with punctures darker than disc, costal margin with 14-17 setigerous punctures bearing long hair-like setae; membrane normally developed, brown with dark, branched veins.

Metathorax. Metapleural evaporatorium narrow and elongated, not reaching lateral margin of metapleuron (Fig. 63), peritreme elongated.

Legs. Anterior femora dark brown, bearing numerous erect light coloured hairs; anterior tibiae moderately broadened apically. Femora of middle pair with 4 wellvisible spines on the ventral side (Fig. 60); middle tibiae 

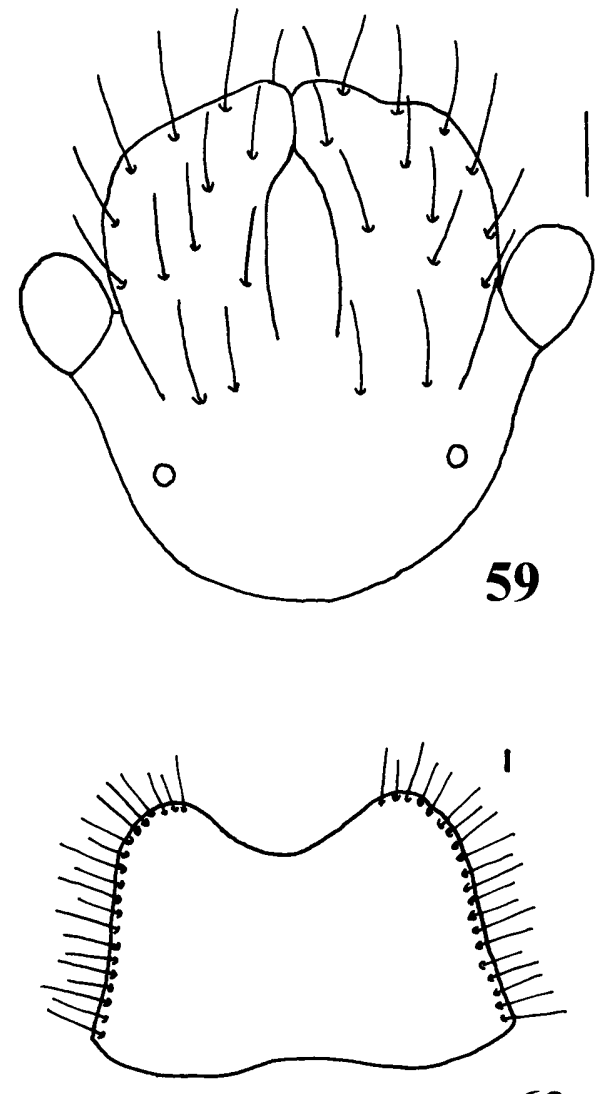

62

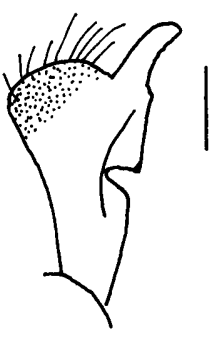

64

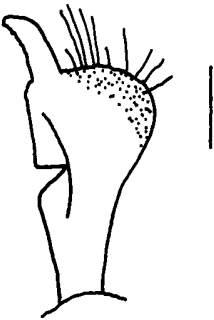

65

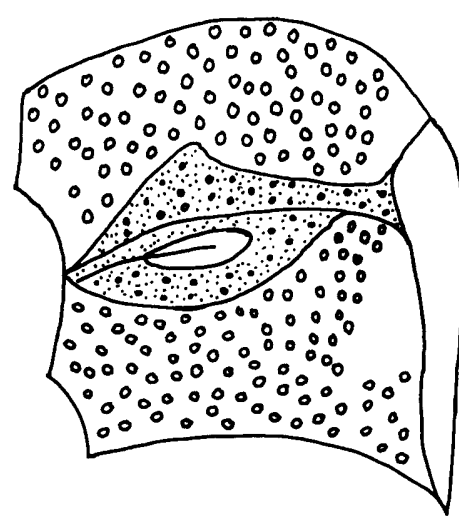

60

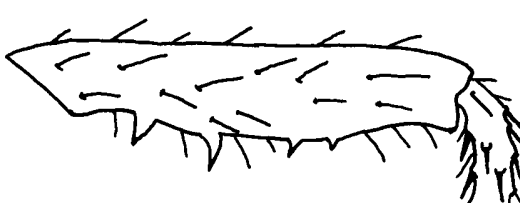

61
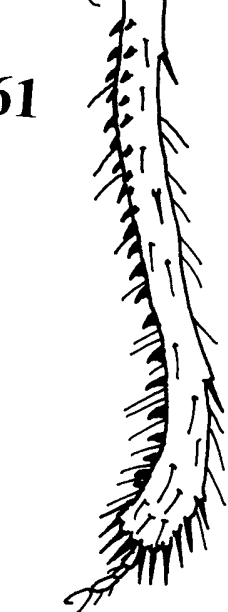

63

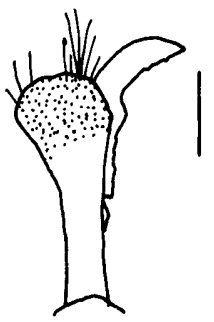

66

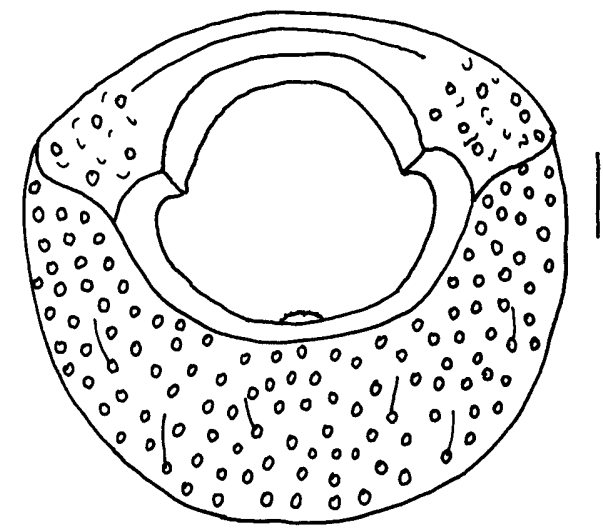

67

Figs 59-67. Blaena pseudosetosa sp. n. 59 - head; 60 - male middle leg; 61 - male hind leg; 62 - pronotum; 63 - evaporatoria on meso- and metapleuron; 64-66 - various views of paramere; 67 - male genital capsule. Scale: $0.1 \mathrm{~mm}$.

straight with black spines. Hind femora with a row of 7 well-developed spines ventrally (Fig. 61); hind tibiae curved apically (Fig. 61), bearing two rows of numerous short black spines on inner margin, pilosity of apical part denser than that of basal.

Abdomen. Sterna black and shiny, convex, vaguely impressed sublaterally, entirely coarsely punctured, except for lateral impunctate band on visible segments IV, and partly III and V; posterior margin of VI sternum with strong spines; lateral margins of each segment with a row of 6 setigerous punctures, and with well-developed posteriorly projecting spine. Male genital capsule as in Fig. 67, paramere as in Figs 64-66.
Material examined. Holotype male: WESTERN AUSTRALIA: Capricorn Road-House, ca. $14 \mathrm{~km} \mathrm{SSE} \mathrm{of} \mathrm{Newman,} 5$ June 1990 R.P. McMillan (WAMP).

Etymology. The species name indicates its similarity to $B$. setosa.

\section{Comparative notes}

This new species is best characterized by the numerous long hair-like setae on head (paraclypeus with about a dozen long hair-like setae, among these 5-6 submarginal ones), and on body margins (lateral submargins of pronotum with a row of 21-23 setigerous punctures bearing long hair-like setae, costal margin with a row of 14-17 setigerous punctures). 
In terms of the pilosity of the body this new species is allied to $B$. multitricha, but differs from the latter in its poorly developed prosternal carinae, as well as in the shape of male genital capsule (Figs 47, 67), paramere (Figs 44-46, 64-66), and hind legs (Figs 41, 61).

Male of this new species is also similar to those of $B$. setosa, but is easily recognizable as its abdominal sterna bear a vague sublateral groove (abdominal sterna sublaterally bear distinct, broad, deep groove in $B$. setosa), and the number of setigerous punctures bearing long hair-like setae on lateral body margins (B. pseudosetosa: pronotum 21-23, costa 14-17; B. setosa: pronotum 9-13, costa 4-6). Moreover, both species differ in the shape of male hind tibiae (Figs 61, 82).

Distribution. Western Australia.

\section{Blaena serrata sp. n.}

(Figs 68-78)

\section{Description}

Body. Length 4.15-4.65 (female), 4.75-4.80 (male Fig. 68).

Head (Fig. 69). Black or blackish brown, shiny, paraclypei coarsely punctured and bearing numerous golden brown, long hair-like setae, among which is a row of 4-6 submarginal setae; lateral margins almost straight anterior to eyes; paraclypei longer than clypeus and joined anteriorly; the latter slightly convex, bare; bucculae with fine hairs; ocular index 3.59-3.71 (male), 3.59-4.88 (female); ocelli small, distance between ocelli about 2.4-2.8 times greater than distance between an ocellus and an eye, ocellar index 10.2-15.3; rostrum extending beyond anterior coxae, but not reaching the middle coxae; length of antennal segments: I $0.22-0.27$, II $0.17-0.27$, III $0.31-0.43$, IV $0.49-0.59$, V $0.63-0.67$.

Prothorax. Pronotum about 1.4-1.5 times broader than long (Fig. 71), black, moderately shiny, disc coarsely punctured and bearing golden brown hairs of different length; anterior margin deeply concave, posterior margin shallowly concave centrally; lateral margins conspicuously serrated, submargins with 18-22 long hair-like setae. Prosternum blackish brown; prosternal carinae well-developed, bearing golden hairs. Propleuron black, coarsely punctured, its anterior margin with golden woolly hairs, lateral parts sparsely, shallowly punctured and finely pilose.

Mesothorax. Scutellum black or blackish brown, slightly wider than long, punctation of disc as dense as that of pronotum, median discal carina well visible in apical part; pilosity of scutellar disc more sparse than that of pronotum. Anterior part of mesopleuron punctured, evaporative area broad, laterally reaching margin of mesopleuron (Fig. 76). Corium blackish brown or dark castaneous, costal margin with $10-13$ setigerous punctures bearing long hair-like setae; membrane brown, normally developed, almost reaching the tip of abdomen (Fig. 68), veins dark, usually straight, sometimes branched to a degree; base of membrane usually with large pale patches.
Metathorax. Metapleural evaporatorium large, reaching about two thirds of metapleuron length, peritreme elongated (Fig. 76).

Legs. Anterior femur castaneous, ventrally bearing light hairs and tubercles; anterior tibiae moderately apically broadened, bearing short dark spines. Femora of middle pair with a row of small spines (Fig. 72); tibiae straight with short black spines (Fig. 72). Male hind femora ventrally with a row of large sharp spines, among these 2-3 clearly larger than remainder (Fig. 70); female hind femora ventrally with a row of small spines; male hind tibiae slightly recurved basally and apically (Fig. 70 ), with a row of small stout black spines on inner margin; female hind tibiae straight, and lacking the row of spines.

Abdomen. Sterna black, convex, lateral submarginal furrow shallow, ventral surface entirely punctured in female, but with lateral impunctate band on segments III and IV in male; posterior margin of V and VI sterna with spines; lateral margins of each segment with a row of 5-6 setigerous punctures, and with well-developed posteriorly projecting spine. Sterna densely covered with erect light hairs. Male genital capsule as in Fig. 77, paramere as in Figs 73-75. Female genital plates rather narrow (Fig. 78), densely punctate.

Material examined. Holotype and 5 paratypes: QUEENSLAND: 1 male (holotype), Homestead, Silver Plains, Via Coen, N. Qld., 11.xii.1964, G. Monteith (UQIC); 1 female, Iron Range, Cape York Pen., N. Qld., 1-9 June, 1971. G.B. Monteith (UQIC); NORTHERN TERRITORY: 2 females, Horn Islet, Pellew Group, N.T., 25-31 Jan. 1968 (1 female), 16-23 May 1968 (1 female), B.Cantrell (UQIC, DBUO); 1 male, South West Is., Pellew Group, 7.ii.1968, B. Cantrell (DBUO); WESTERN AUSTRALIA: 1 male, Geraldton \& Mullewa, W.A., Lea, Pres. by Com. Inst. Ent. B.M. 1948-548 (BMNH).

Etymology. The species name refers to the serrated lateral margins of pronotum.

\section{Comparative notes}

This new species is characterized by numerous long hair-like setae on surface of head (each paraclypeus with about a dozen long hair-like setae, including 4-6 submarginal ones), body margins (lateral submargin of pronotum has a row of 18-22 setigerous punctures bearing long hair-like setae, costal margin with a row of 10-13 setigerous punctures bearing long hair-like setae), and by densely pilose prosternal carinae, and serrated lateral margins of pronotum.

In terms of its body pilosity this new species is allied to B. cirra, but differs from the latter in the conspicuously serrated lateral margins of pronotum (margins of pronotum are not serrated in $B$. cirra). On the other hand, this new species, at first glance, also resembles the macropterous forms of $B$. hirta and $B$. tamasi, but can easily be recognized by the numerous setigerous punctures on body margins (see above), whereas both $B$. hirta and $B$. tamasi have fewer (head - 3 and 1, respectively; pronotum 8-10 and 5-6, respectively; costa - setigerous punctures absent in both these species). 


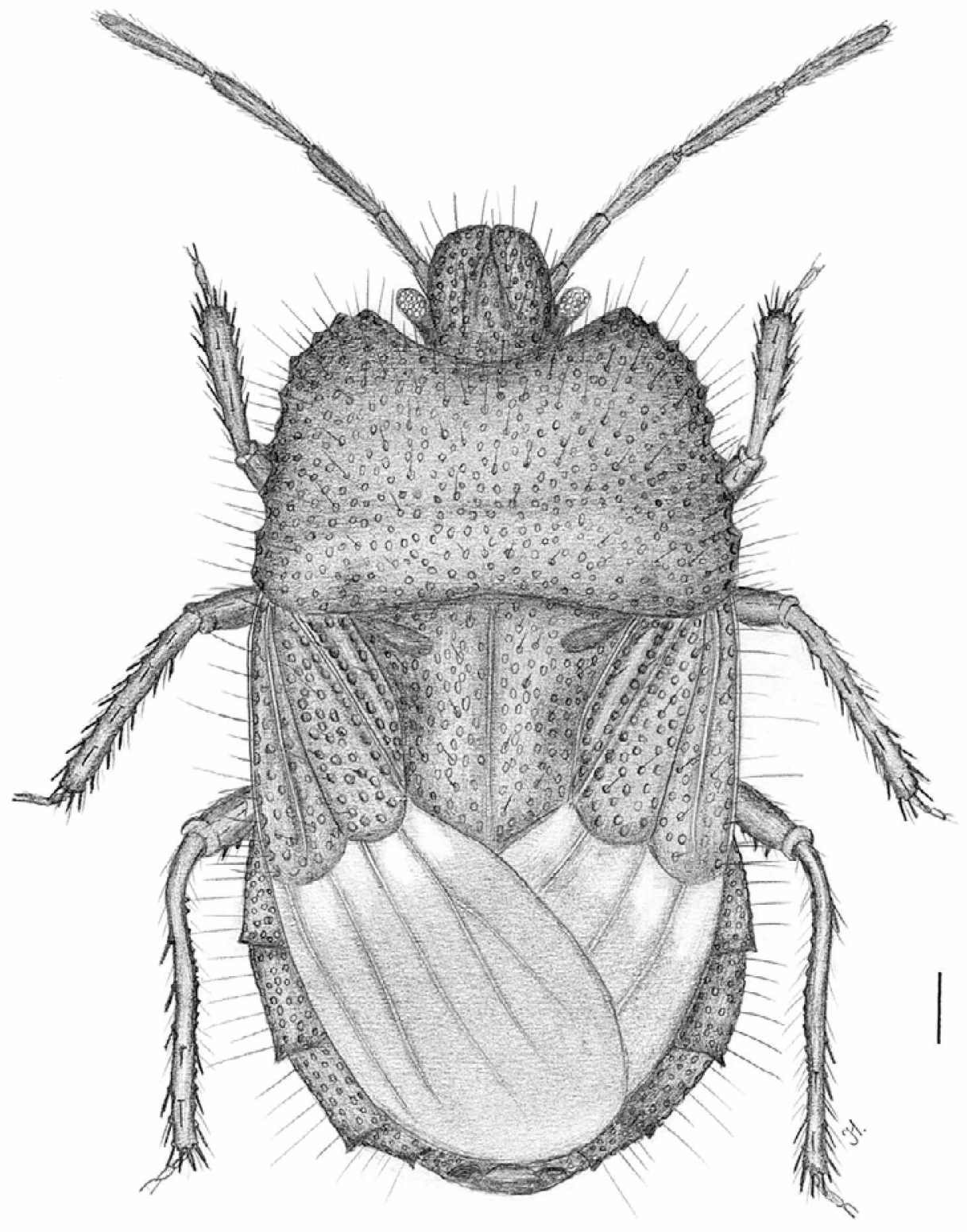

Fig. 68. Blaena serrata sp. n. - dorsal view. Scale: $0.3 \mathrm{~mm}$.

Distribution. Northern Territory, Queensland, Western Australia.

\section{Blaena setosa Walker, 1868}

(Figs 79-89)

Blaena setosa Walker, 1868: 538; Distant, 1899: 224; Froeschner, 1960: 462, 1966: 690; Lis, 1995: 139, 1996: 185 .

Macrhymenus membranaceus Signoret, 1880a: 25 [1880b: XVIII]; syn. with Blaena setosa by Distant, 1899: 224.

\section{Redescription}

Body. Length 5.60-6.40 (female), 5.50-6.95 (male Fig. 79).
Head (Fig. 80). Black, shiny, coarsely punctured; paraclypei longer than clypeus and joined anteriorly, forming two triangular projections apically; clypeus moderately convex, bare; each paraclypeus with a submarginal row of 3 long hair-like setae; bucculae with fine hairs; ocular index 3.45-4.21; ocelli small, distance between ocelli about 2.1-3.8 times greater than the distance between an ocellus and an eye, ocellar index 7.0-14.0; rostrum extending beyond anterior coxae, but not reaching the middle coxae; length of antennal segments: I $0.24-0.38$, II 0.35-0.45, III 0.41-0.63, IV 0.56-0.73, V 0.56-0.71.

Prothorax. Pronotum black or blackish brown, shiny, coarsely punctured, about $1.45-1.50$ times broader than long (Fig. 83); its dorsal surface with scattered golden brown hairs; anterior margin deeply broadly concave, 

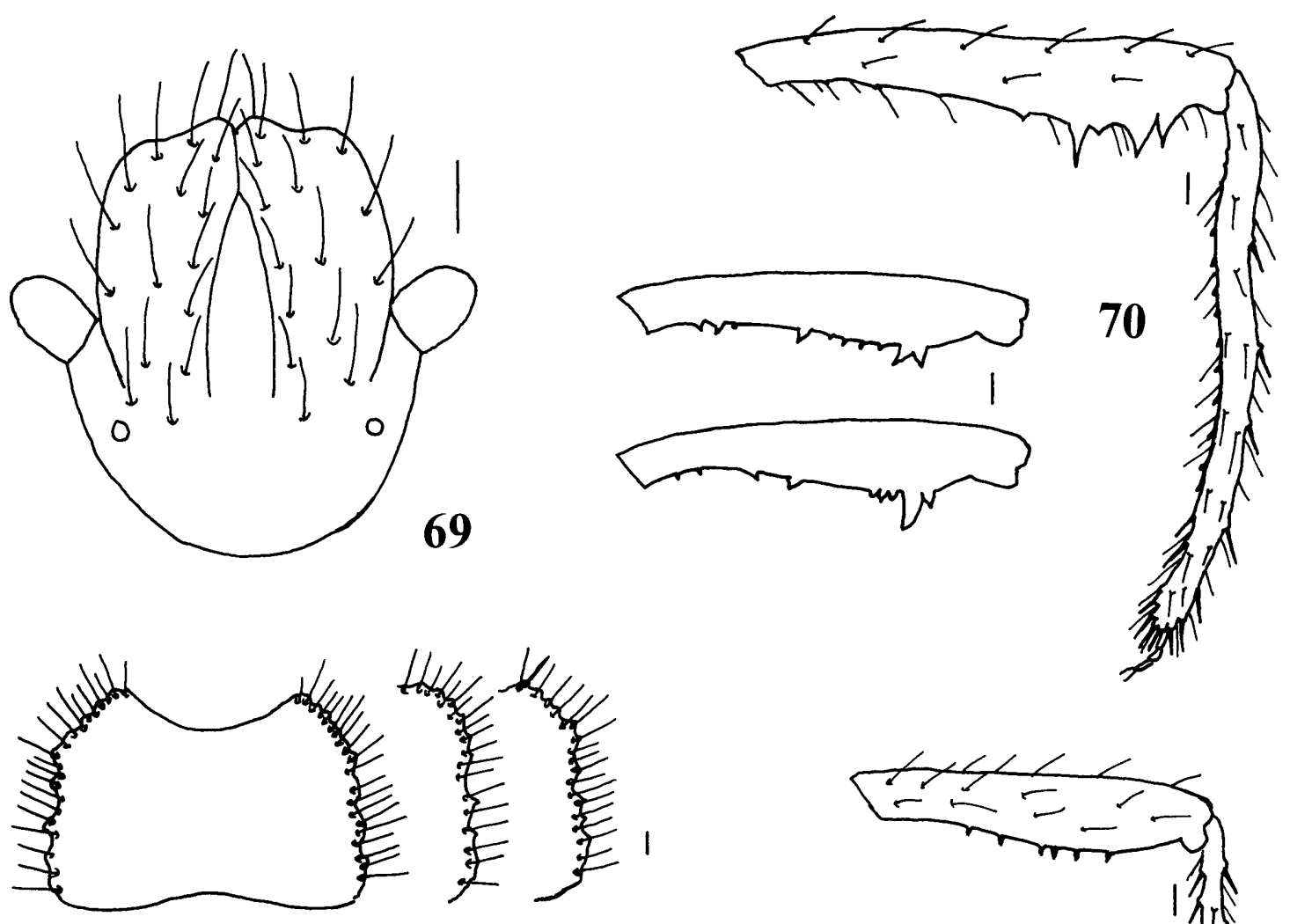

71

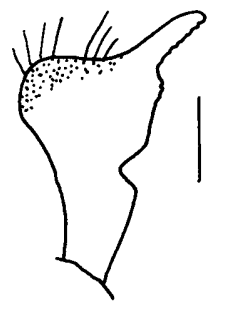

73

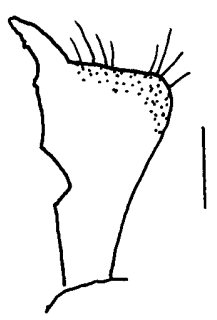

74

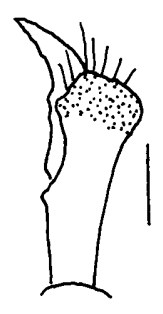

75
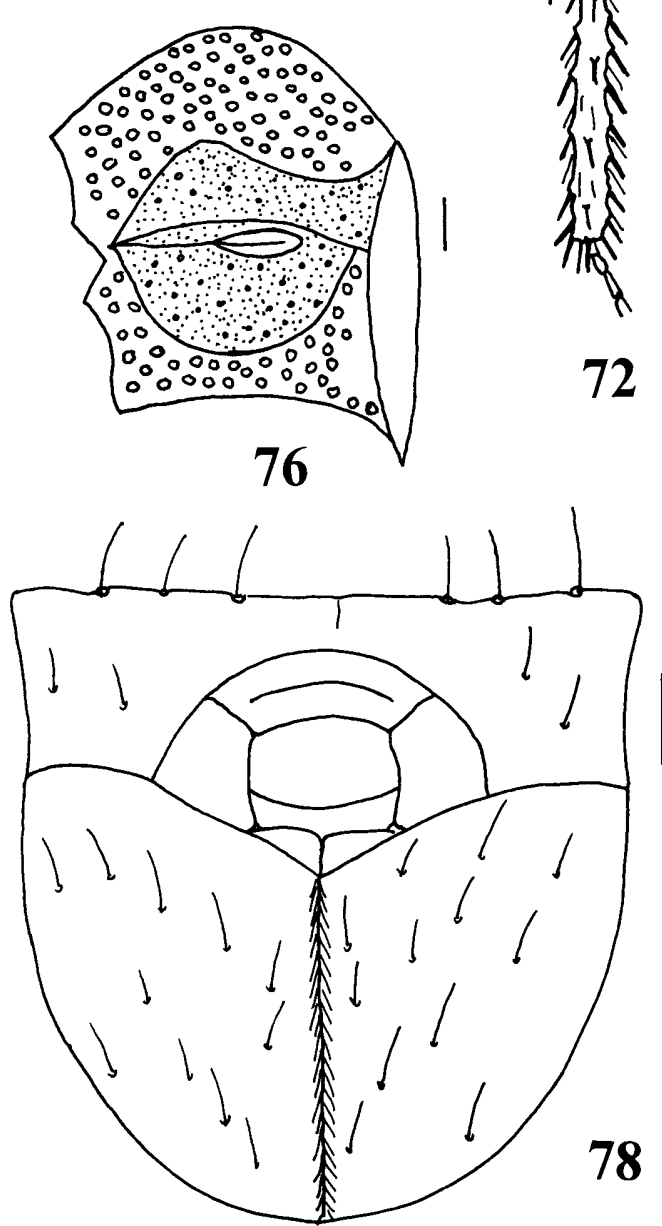

72

8

77
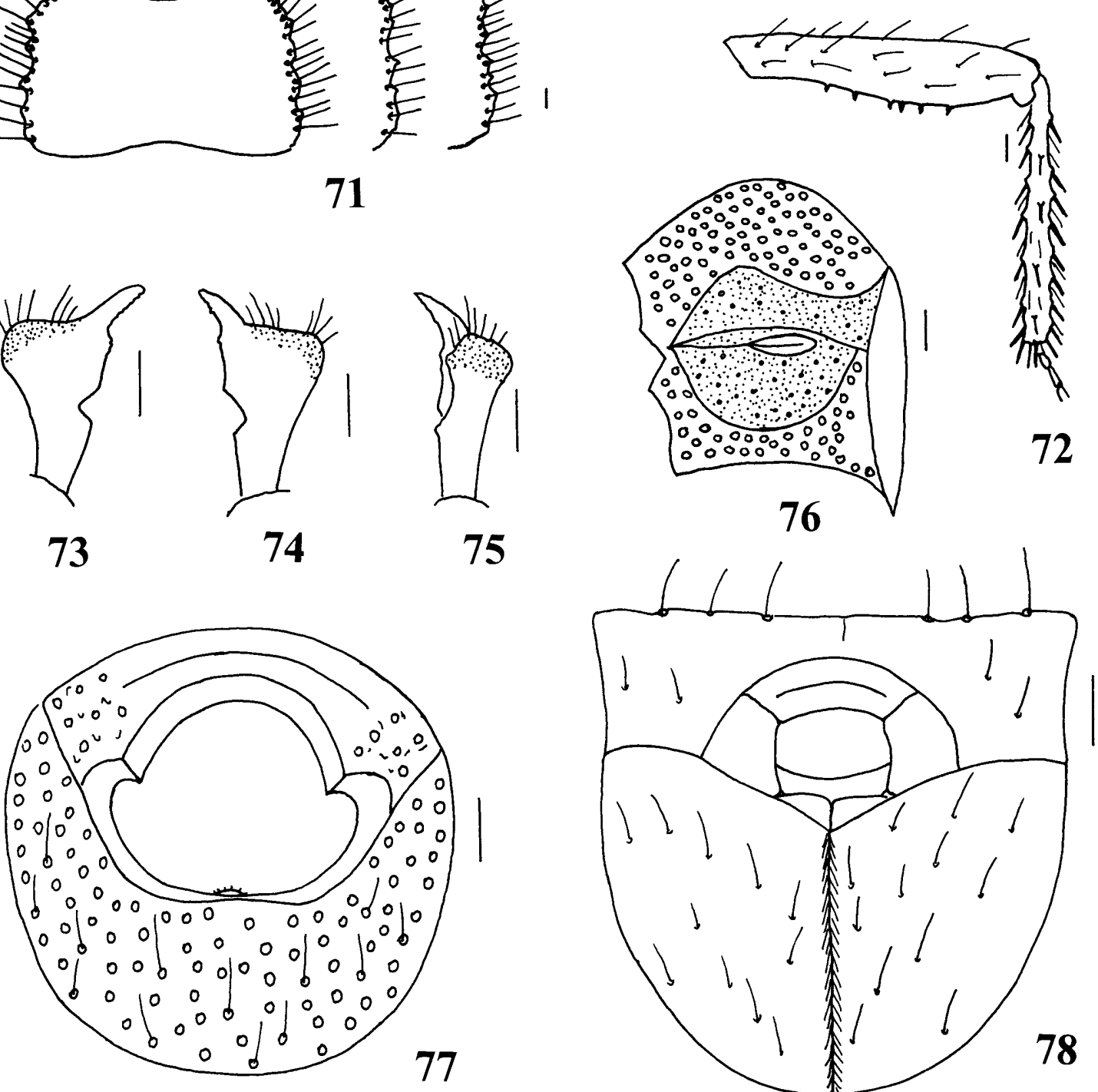

Figs 69-78. Blaena serrata sp. n. 69 - head; 70 - male hind leg, and variability in the arrangement of spines on femur; 71 - pronotum; 72 - middle leg; 73-75 - various views of paramere; 76 - evaporatoria on meso- and metapleuron; 77 - male genital capsule; 78 - female genital plates. Scale: $0.1 \mathrm{~mm}$. 
posterior margin concave centrally; lateral margins not serrated, narrowed anteriorly, each submargin with a row of 9-13 setigerous punctures bearing long hair-like setae; transverse postmedial impression shallow. Prosternum black or blackish brown, coarsely punctured; prosternal carinae very low, almost invisible, at first sight apparently absent. Propleuron black, shiny, coarsely and deeply punctured, lateral parts shallowly impunctate.

Mesothorax. Scutellum black with margins and apex more castaneous in colour, wider than long, punctation of disc crowded and coarse, median discal carina weakly developed, usually clearer apically; pilosity of scutellar disc sparse. Anterior part of mesopleuron punctured, evaporative area narrowed laterally to reach margin of mesopleuron. Corium castaneous or dark brown, its punctation sparser than that on pronotum and scutellum, punctures large, pilosity fine and sparse; costal margin with 4-6 setigerous punctures bearing long hair-like setae; membrane normally developed, usually narrower than abdomen, reaching or almost reaching the tip of abdomen, only sometimes surpassing it, veins simple or furcate, sometimes reticulate, darker than the remaining surface of membrane.

Metathorax. Metapleural evaporatorium broad centrally, laterally narrowed, peritreme elongated.

Legs. Anterior femur brown, bearing setigerous punctures on ventral side; anterior tibia clearly broadened apically (Fig. 81). Femora of middle pair with rows of small sharp spines ventrally; middle tibiae straight with black spines. Male hind femora ventrally with a row of strong spines (Fig. 82), the median one usually clearly longer and stouter; female hind femora ventrally with a row of short blunt tubercles; male hind tibiae with basal twothirds strongly bowed outward (Fig. 82), apical third almost straight, ventral margin of basal two-thirds with two rows of strong tubercles and numerous long hairs; female hind tibiae straight, unmodified.

Abdomen. Sterna clearly impressed sublaterally, furrow along their lateral margins deep and welldeveloped; sterna ventrad of furrow coarsely punctured and bearing numerous setigerous tubercles (better developed in males than females), punctures in furrow much finer than elswhere on sterna; lateral margins of each segment with a row of 3-4 setigerous punctures, and with well-developed posteriorly projecting spine. Male genital capsule as in Fig. 88, paramere as in Figs 85-87. Female genital plates narrow (Fig. 89), densely punctate.

Material examined. LOCALITY UNKNOWN: Holotype (by monotypy) female (as lectotype by Froeschner, 1960: 463) of Blaena setosa Walker (BMNH). AUSTRALIA: Lectotype male (designated by Froeschner, 1960: 463) of Macrhymenus membranaceus Signoret: Australia (NHMW); NEW SOUTH WALES: 2 males 4 females, $20 \mathrm{mi}$. W of Broken Hill, N.S.W., 20.viii.1969, G.B. Monteith (UQIC, DBUO); 1 male, Nyngan dist., Feb. 1-9 1960, under logs, J.W. Armstrong (UQIC); NORTHERN TERRITORY: 2 males 1 female, $206 \mathrm{~km} \mathrm{~N}$ Tennant Ck., 23 Nov. 1978, R.I. Storey, at light (QPIM, DBUO); 1 male, 16.07'S 129.01'E, Lake Arygyle, M.V. light, 15 Nov. 1984, M. Malipatil (MAGD); 1 female, 15.19'S 131.33'E,
Brandy Bottle Yard Ck., M.V. light, 10 Nov. 1984 , M. Malipatil (MAGD); 1 female, 19.34'S 134.13'E, Tennant Creek, G. Medvedev, 10.XI.79 (ZMAS); 1 male 1 female, 19.34'S 134.13'E, Tennant Creek, Zaitzev, 10.XI.79 (ZMAS, DBUO); 1 male, 12.19'S 132.51'E, Ja Ja, 12.X.1977, R. Pergilley (MAGD); 1 male, Horn Islet, Pellew Group, 25-31 Jan. 1968, B. Cantrell (UQIC); 1 female, Lake Woods, $11 \mathrm{~km} \mathrm{SW} \mathrm{Elliot,} \mathrm{at} \mathrm{light,} 5$ Oct. 1977, G.F. Gross \& J.A. Forrest (SAMA); 1 female, Grodi Eylanst, 17-23.vi.1982, J.I. Majer, in pit-fall trap in open forest (MAGD); 1 female, Barkly Tableburd, Lanewood Site, 2.x.1976, R. Pergilley (MAGD); 2 males 1 female, Mt. Cavanagh, 25.VIII. 59, N.T., E.M. Exley (UQIC); SOUTH AUSTRALIA: 4 males 2 females, $6.4 \mathrm{~km} \mathrm{~N}$ Coward Springs, 9 Nov. 1966, G.F. Gross (SAMA, DBUO); 1 female, Gawler Ranges, Kolay Dam, 32.33'S 135.36'E, Paney Stn., Pitfalls, 7-11 Dec. 1989, J. Forrest (SAMA); 2 females, on Salt Lake Heart, 12 Nov. 1970, G.F. Gross (SAMA, DBUO); 1 male, Nr. Victory Well, Everard Pk. Stn., 3 Nov. 1970, E.G. Matthews (SAMA); 1 male 1 female, 160-209 km. W Mabiel Ck., hs on emu rd., April 1994, G.F. Gross (SAMA, DBUO); 1 male 1 female, S. Australia, coll. Nickerl, Mus. Pragensis (NMPC); 3 males 1 female, Nr. Arcoona Station, the pines (SAMA); 6 males 2 females, Woodforde Ck., Andamooka Rgs., 1 Sept. 1948, G.F. Gross, Blaena setosa, det. R.C. Froeschner (SAMA); 1 female, Lake Eyre., 11 Dec. 1951, G.F. Gross, Blaena setosa, det. R.C. Froeschner (SAMA); 1 male, Mt. Remarkable, Oct. 1925., F.E. Wilson, Blaena setosa, det. R.C. Froeschner (SAMA); QUEENSLAND: 1 male, N. Q1d., Hann River, N. Laura, 5 Sept. 1978, R.I. Storey, at light (QPIM); 2 males, SEQ: 25041'S x 151026'E, Nipping Gully, Site 7, 25 Jan - 2 Jun 1999, 320m, Monteith \& Thompson, open for., pitfall, 7714 (QMBA, DBUO); 1 male, Bynya Mts, S.E. Qld., 16-19.xi.1967, G.B. Monteith (UQIC); VICTORIA: 1 male 1 female, Lake Hattech, J.E. Dixon collection, Jan. 1940, Blaena setosa, det R.C. Froeschner (MVNH); WESTERN AUSTRALIA: 8 males 6 females, Geraldton, Austral. (NMPC, DBUO); 1 male, 18.05'S 128.47'E, Nicholson R., M.V. light, 14 Nov. 1984, M. Malipatil (MAGD); 1 male, Broome, 14-17 Dec. 1975, E. Exley \& R. Storey (UQIC); 7 males 2 females, Eneabba, 9 July 1987, R.P. McMillan, Minesite rehab. area, on ground (WAMP, DBUO); 1 male, Peak Charles, 32.53'S $121.10^{\prime} \mathrm{E}$ and vicinity, 6-8 April 1985, T.F. Houston (WAMP); 1 male 1 female, $4 \mathrm{~km}$ of Meekathara, 4 June 1990, R.P. McMillan (WAMP); 2 males 3 females, Bungabiddy Rockhole, Walter James Ra. 24.39'S 128.45'E, 15-16 Jan 1990, T.F. Houston \& M.S. Harvey, at light MV (WAMP, DBUO); 1 male 1 female, Winburn Rocks, 26.05'S 127.30'E, $94 \mathrm{~km}$ E Warburton, 22 Jan. 1990, T.F. Houston \& M.S. Harvey, at light (gas \& mv) (WAMP); 1 male 2 females, Tarin Rock reserve, 33.06'S 118.13'E, 19-21 Dec. 1987, T.F. Houston, at light (mv), at night (WAMP, DBUO); 1 male, F.H. Father Baker Meadow Station, Murchison dist., 28.8.67 (SAMA); 1 male 1 female, Meekantharra-Billiluna Pool, Canning Stock, Rte. Exp. Apr. 1930-Aug. 1931, Blaena setosa, det. R. C. Froeschner (SAMA); 2 males 2 females, Beverley, E.F. Boulay, Blaena setosa, det. R.C. Froeschner (SAMA); 1 male, Mullewa, W.D. Dodd, Blaena setosa, det. R.C. Froeschner (SAMA).

Distribution. New South Wales (first record), Northern Territory (first record), Queensland, South Australia, Victoria, Western Australia.

\section{Blaena subsulcata Froeschner, 1960}

(Figs 90-96)

Blaena subsulcata Froeschner, 1960: 464, 1966: 690; Lis, 1995: 139, 1996: 185. 


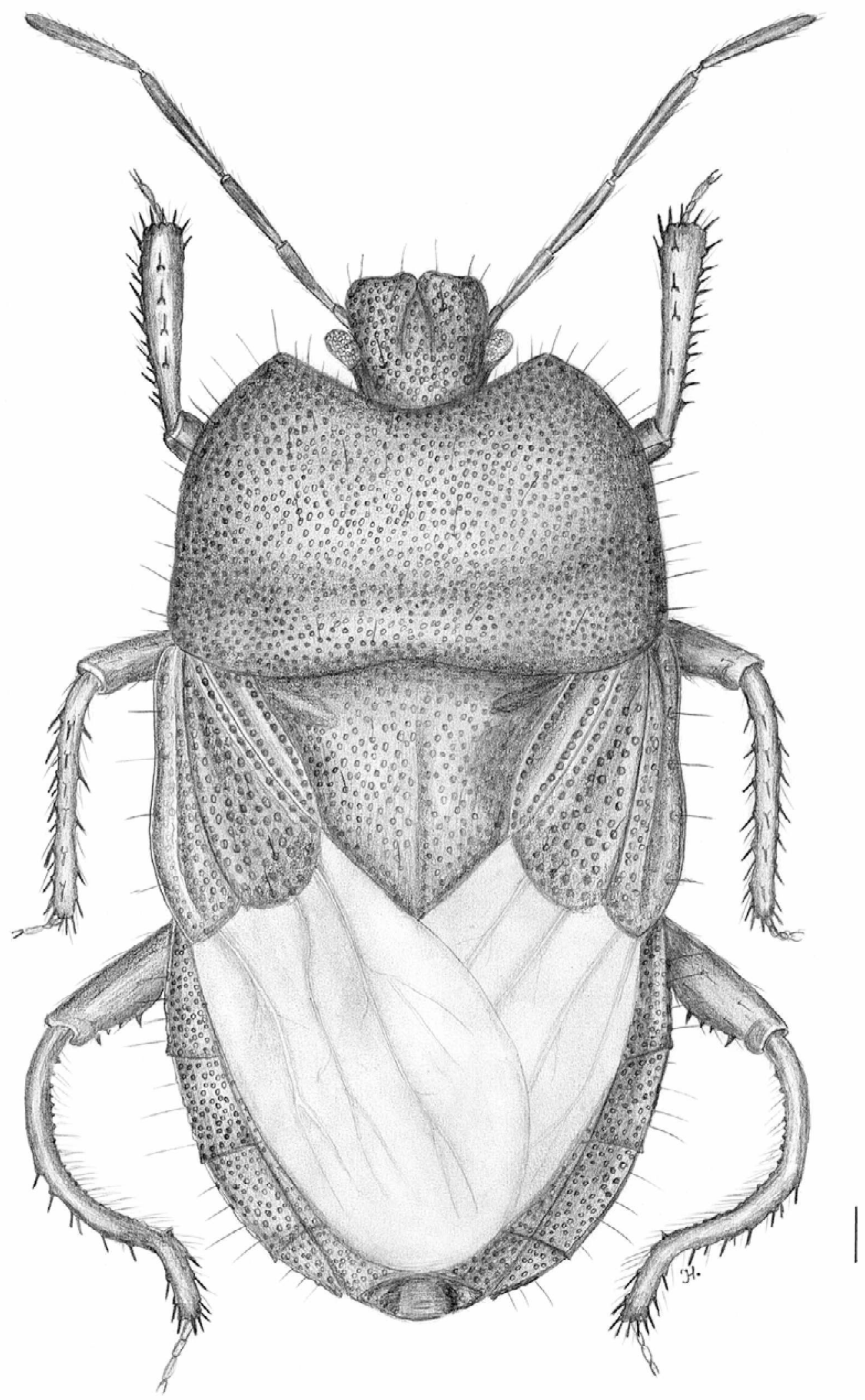

Fig. 79. Blaena setosa Walker - dorsal view. Scale: $0.3 \mathrm{~mm}$.

\section{Redescription}

Body. Length 5.75-6.14 (female), 5.87-6.30 (male).
Head (Fig. 90). Black, shiny, paraclypei coarsely punctured; anterior outline diverging from preocular emargination, broadly rounded at apex; paraclypei longer than clypeus and joined anteriorly; the latter strongly convex; 

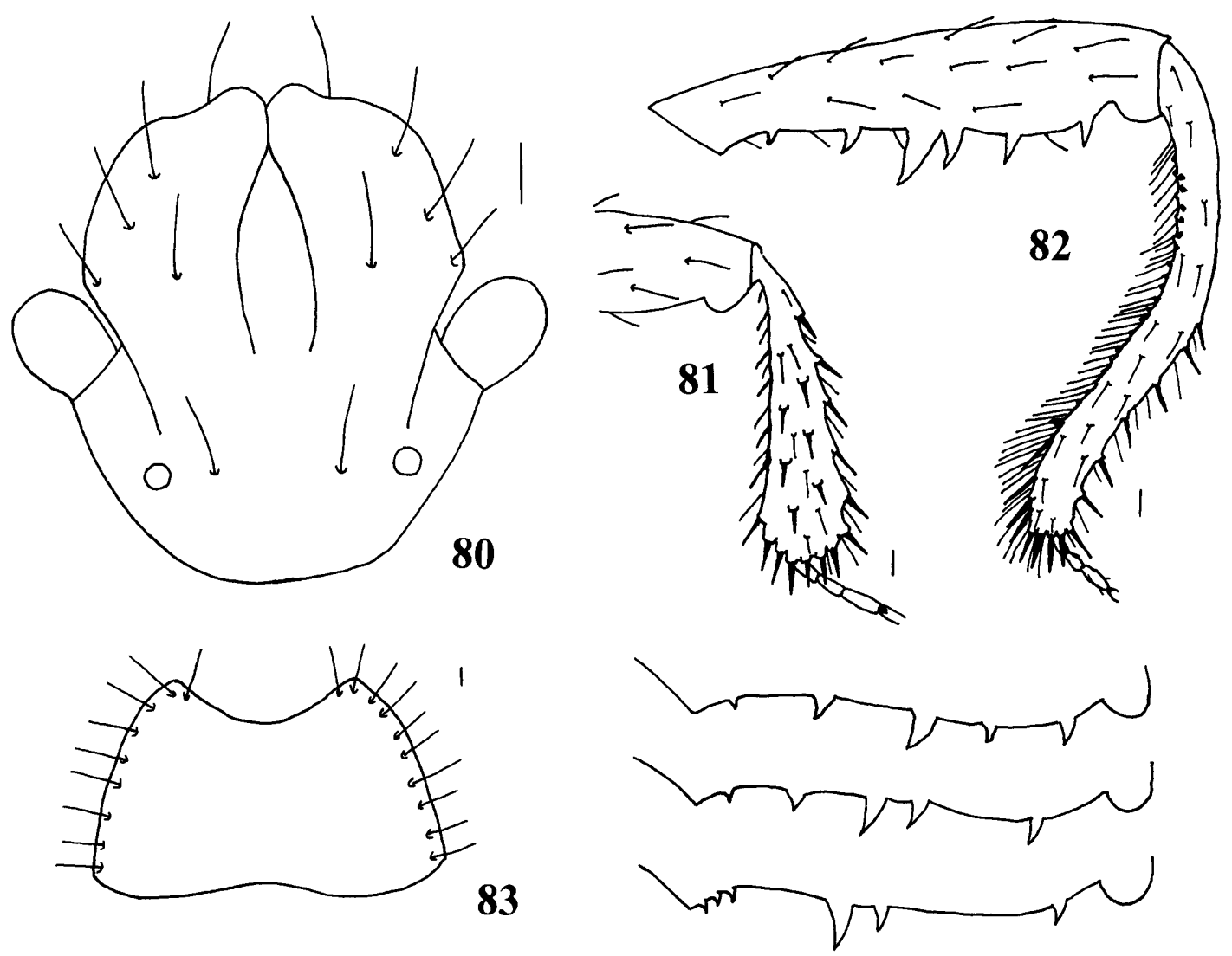

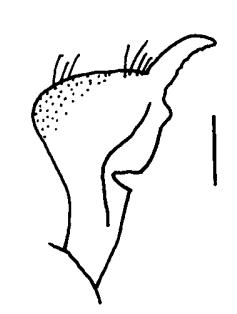

85

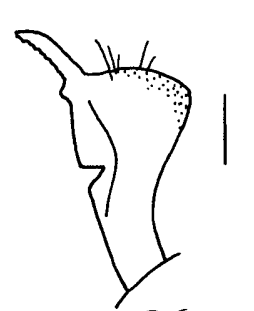

86

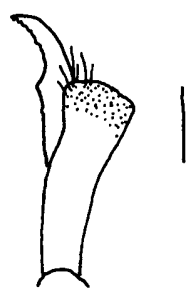

87

83
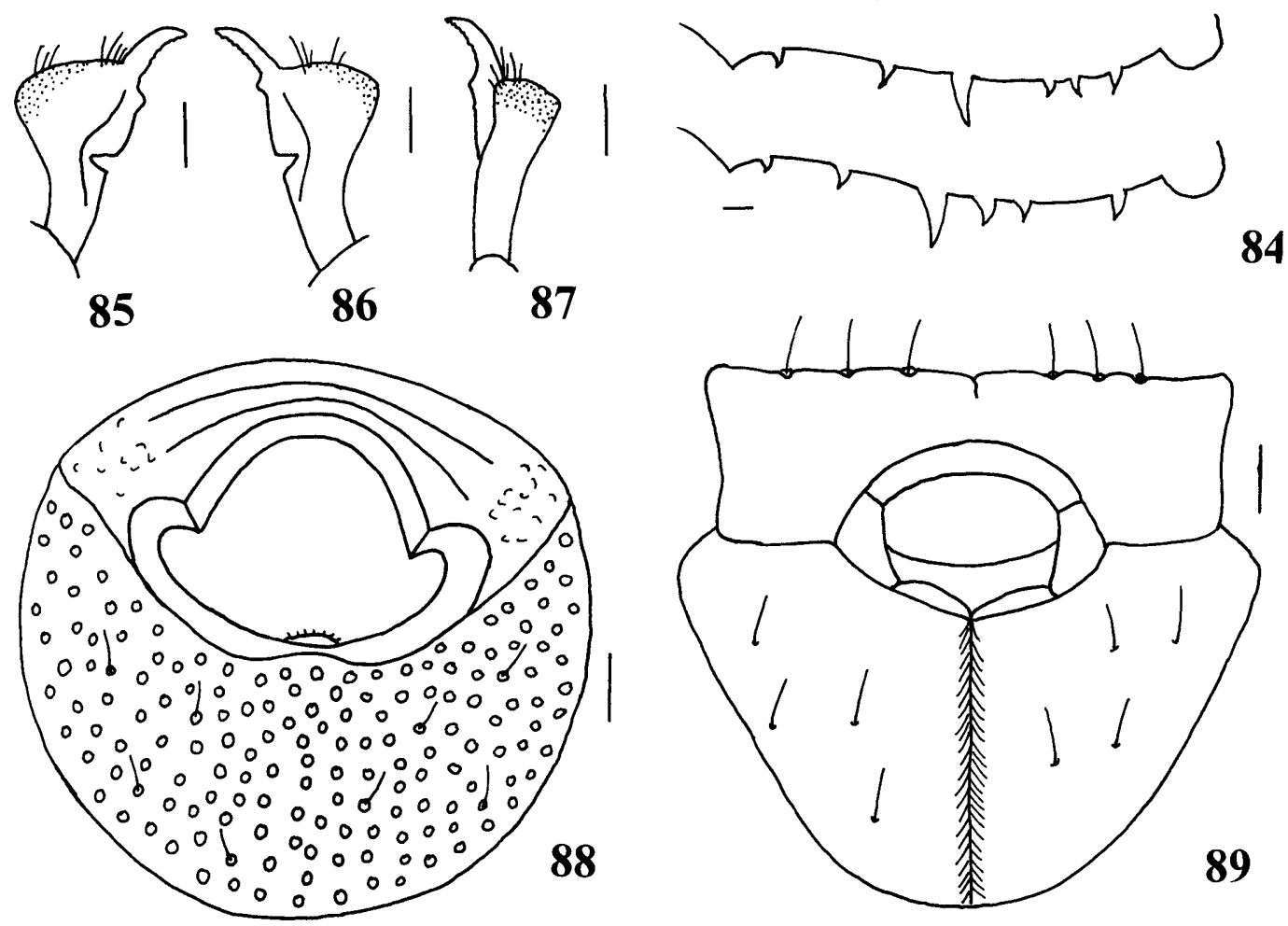

Figs 80-89. Blaena setosa Walker. 80 - head; 81 - anterior tibia; 82 - male hind leg; 83 - pronotum; 84 - variability in the arrangement of spines on male hind femur; 85-87 - various views of paramere; 88 - male genital capsule; 89 - female genital plates. Scale: $0.1 \mathrm{~mm}$. 
paraclypei forming a strong, irregular ridge on either side of clypeus, each paraclypeus with four setigerous punctures bearing long hair-like setae, among them a single preocular; bucculae almost parallel-sided, bare; eyes castaneous, ocular index 3.86 (male), 3.33-3.64 (female); ocelli small, distance between ocelli about 2.3-4.4 times greater than distance between an ocellus and an eye, ocellar index 8.0-8.2; rostrum extending beyond anterior coxae, but not reaching the middle coxae; length of antennal segments: I $0.23-0.29$, II $0.23-0.28$, III 0.54-0.66, IV 0.67-0.76, V 0.69-0.86.

Prothorax. Pronotum about 1.5-1.8 times broader than long (Fig. 91), black, shiny, coarsely punctured; anterior margin deeply broadly concave, posterior margin almost straight; lateral margins weakly explanate, with a small prebasal angular projection; each submargin with a row of 4-5 setigerous punctures bearing long hair-like seta on anterior lobe, and a single setigerous puncture on the prebasal projection of posterior lobe (Fig. 91); transverse postmedial impression deep and well-developed; midline weakly carinate. Prosternum black, punctured; prosternal carinae well-developed, high, bearing a few hairs. Propleuron black, coarsely punctured, its anterior margin bare, lateral parts shallowly punctured, bare.

Mesothorax. Scutellum black, apically somewhat paler, bare, as wide as or slightly wider than long, punctation of disc dense, midline sometimes broadly but weakly sulcate from base to past middle, sometimes sulcus hardly visible, apex with well developed median carina, usually paler than remaining part of disc. Anterior part of mesopleuron punctured; evaporative area elongated, reaching lateral margin of mesopleuron. Corium blackish brown or dark castaneous, coarsely punctured, costal margin without setigerous punctures; membrane pale brown, semihyaline, normally developed, narrower than abdomen and almost reaching its tip, veins dark brown, irregularly reticulate; base of membrane with pale irregular spots.

Metathorax. Metapleural evaporatorium large, almost reaching lateral margin of metapleuron, peritreme strongly elongated.

Legs. Femora dark brown, finely pilose, without spines; tibiae straight, brown, bearing short black fine spines and pale hairs; anterior tibiae subterete; male posterior femora and tibiae unmodified.

Abdomen. Sterna convex, weakly impressed sublaterally, black or blackish brown, shiny, punctation laterally denser and coarser than medially, bearing lateral impunctate band on visible segments IV in males; lateral margin of each segment without or with a single setigerous tubercles, and with small, sometimes hardly visible posteriorly projecting spine. Male genital capsule as in Fig. 96, paramere as in Figs 92-94. Female genital plates very broad (Fig. 95), sparsely punctate.

Material examined. NORTHERN TERRITORY: 1 female, King River, 24.12.65, Blaena subsulcata Frschn., comp. with type, R.C. Froeschner'61 (MVNH); QUEENSLAND: 1 male,
S.E. Qld., Somerset Dam, 24.iii.1971, G.B. Monteith (UQIC); 1 female, $10 \mathrm{~km} \mathrm{E}$ of Heathlands Airstrip, Cape York Pen., N. Qld., 5.vii.1975, G.B. Monteith (QMBA).

Distribution. Northern Territory, Queensland.

\section{Blaena tamasi J.A. Lis, 1999}

(Figs 97-106)

Blaena tamasi J.A. Lis, 1999a: 53.

\section{Redescription}

Body (Figs 97, 98). Small, 2.65-2.88 in length, elongate, sides subparallel, dorsally weakly convex. Dorsum and venter with crowded, coarse punctures, and numerous clearly visible semierect, recurved apically, shiny hairs. Entire body blackish brown, with lateral margins, hemelytra, antennae and legs more brown or even castaneous in colour; tarsi and rostrum yellowish brown; membranal rim ochreous, more or less dusky, usually paler at base.

Head (Figs 99, 100). About 1.5 times wider than long, lateral margins subparallel, slightly concave in a front of eyes; paraclypei longer than clypeus and joined anteriorly; each paraclypeus with 4-5 setigerous punctures bearing long hair-like setae, among these 2-3 submarginal ones; bucculae finely pilose, narrowed posteriorly; eyes small, ocular index 3.7-4.1, ocelli very small; rostrum reaching posterior coxae; length of antennal segments: I $0.14-0.15$, II $0.08-0.09$, III $0.28-0.29$, IV $0.30-0.33$, V $0.39-0.44$.

Prothorax. Pronotum (Figs 97, 98, 101) about 1.7-1.8 times broader than long, its anterior margin deeply concave, the posterior margin concave in the middle, lateral margins flattened and expanded, with 5-6 distinct projections each bearing basally long hair-like seta; transverse postmedial impression shallow. Prosternum black, punctured; prosternal carinae high, well visible, bearing fine golden hairs. Propleuron coarsely punctured, its anterior margin bearing woolly hairs, lateral parts sparsely punctured, almost bare.

Mesothorax. Scutellum subtriangular, very short, 1.3-1.4 times wider long (Figs 97, 98); punctation and pilosity of scutellar disc similar to that of pronotum; median line hardly visible, carinate to a degree apically. Mesopleuron punctured, mesoplaural evaporatorium reaching lateral margin of mesopleuron. Staphylinoid form (Fig. 97) with corium reduced to triangular pads reaching to intersegmental suture $3 / 4$ of abdomen, clavus unseparated from corium and membrane very narrow, rim-like; hind wings present, small and subtriangular, reaching the base of 3rd abdominal segment. Macropterous form (Fig. 98) with corium normally developed and divided into clavus, meso- and exocorium, and normally developed membrane, not reaching the tip of abdomen. Costa flattened and expanded, bearing numerous recurved hairs, but without setigerous punctures.

Metathorax. Metapleural evaporatorium small, not reaching lateral and posterior margins of metapleuron.

Legs. Femora unarmed, only the posterior ones with very small ventral tubercles in males; anterior tibiae only 


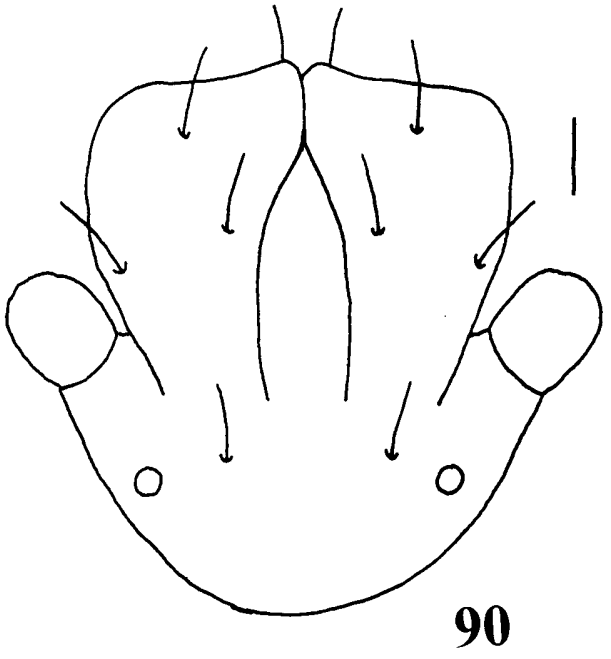

90
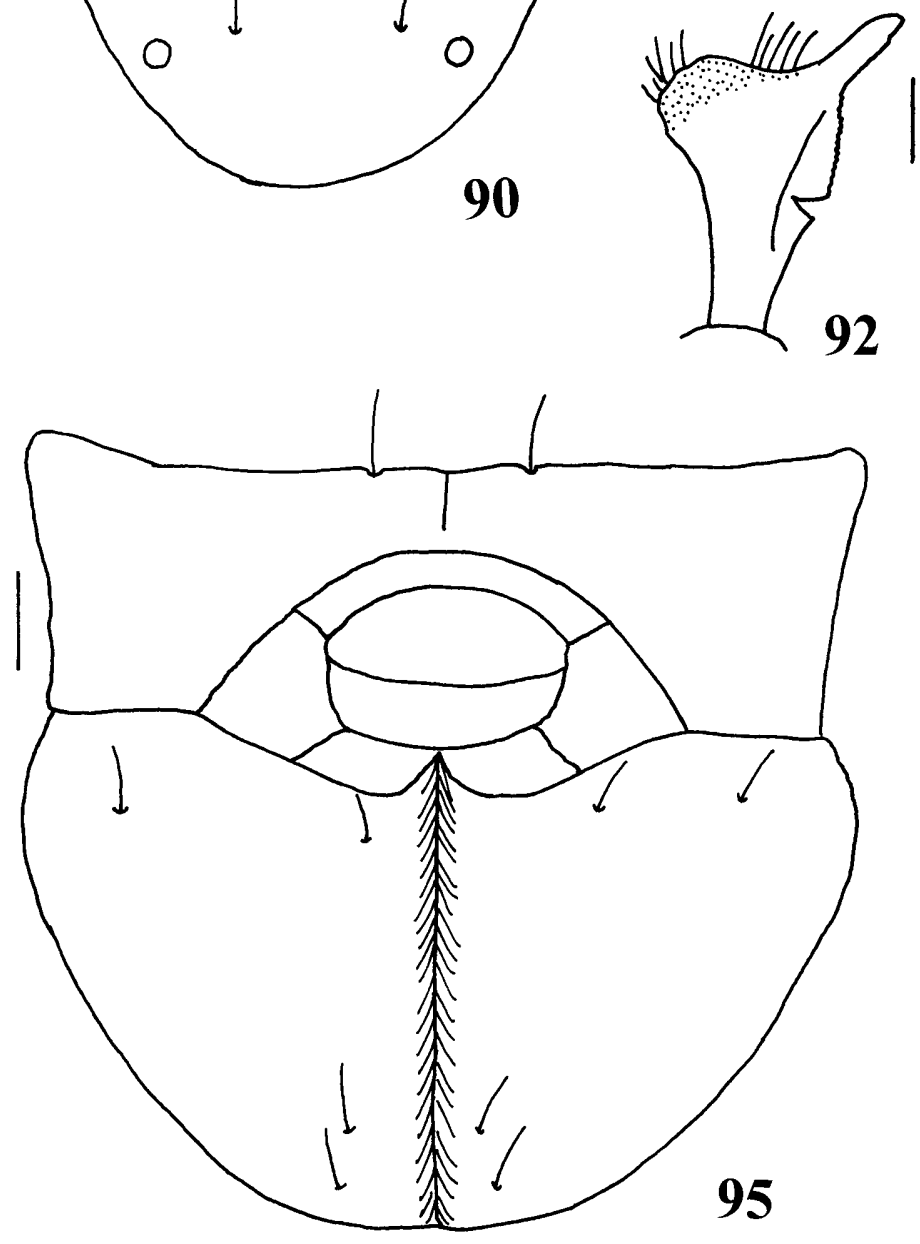

92
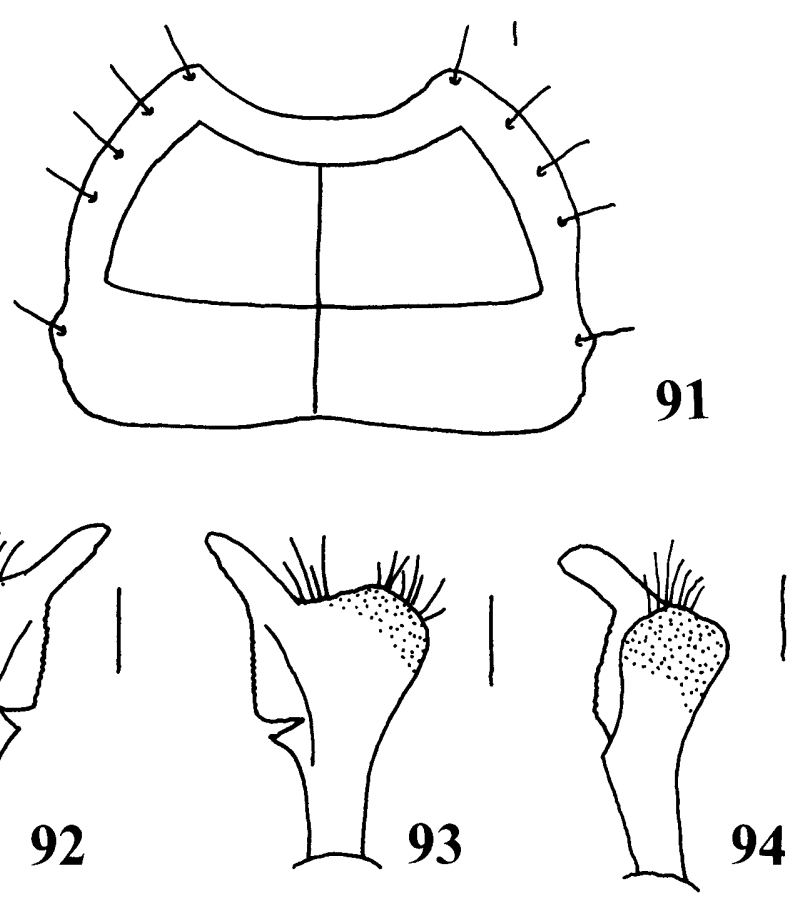

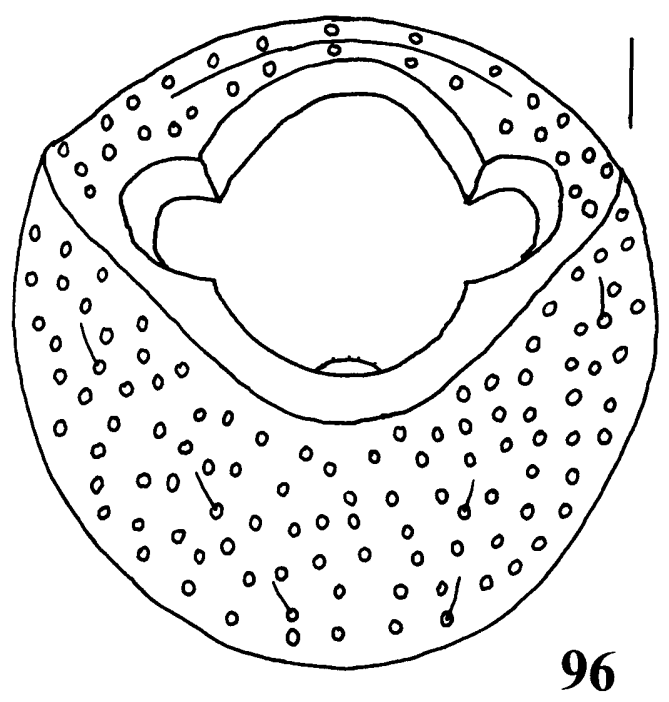

Figs 90-96. Blaena subsulcata Froeschner. 90 - head; 91 - pronotum; $92-94$ - various views of paramere; 95 - female genital plates; 96 - male genital capsule. Scale: $0.1 \mathrm{~mm}$.

slightly broadened apically; posterior tibiae straight with short dark spines and short pale coloured hairs.

Abdomen. Sterna convex, without a lateral, submarginal furrow, surface closely and coarsely punctured and bearing semi-erect shiny hairs, except for shiny lateral impunctate band on visible segments IV in males (partly also on III and V segments); posterolateral angles of each pregenital segment distinctly projecting. Male genital capsule as in Fig. 105, paramere as in Figs 102-104. Female genital plates narrow (Fig. 106), densely punctate.
Material examined. WESTERN AUSTRALIA: 1 male (holotype) 2 males (paratypes) 2 females (paratypes), W. Australia, Treen Brook S.F., No. 1492, 25.I.1979-6.III.79, pit trap (ANIC, HNHM, DBUO); 3 males (paratypes) 1 female (paratype) 1 female (macropterous), W. Australia, Gleneagle S.F., No. 1487, 25.I.1979-6.III.79, pit trap (HNHM, DBUO).

Distribution. Western Australia.

\section{Remarks}

This species was hitherto known only from specimens with staphylinoid wing modification; fortunately, we have also examined one macropterous female in this study. It has all the same characters but for the normally developed 


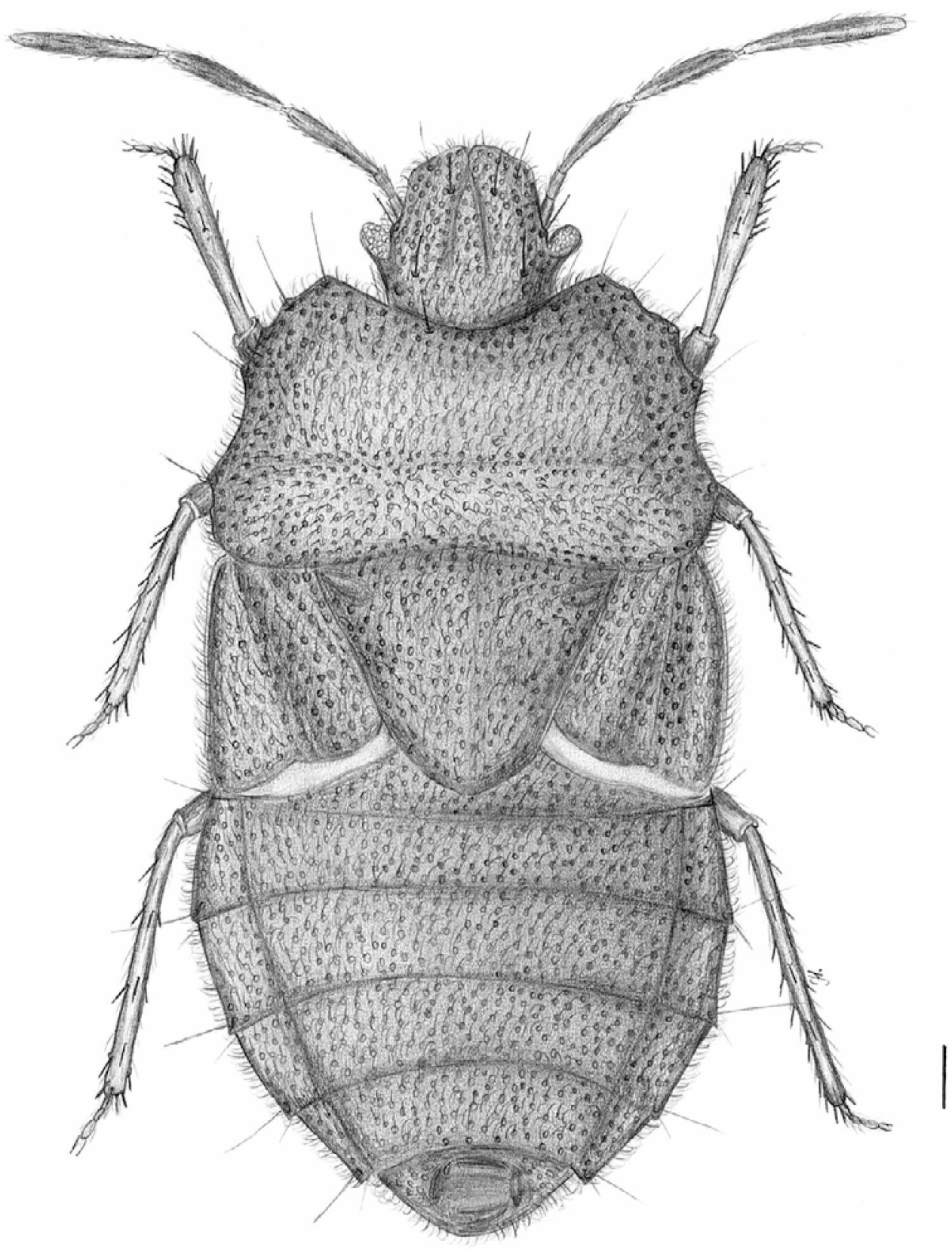

Fig. 97. Blaena tamasi J.A. Lis, staphylinoid form - dorsal view. Scale: $0.15 \mathrm{~mm}$.

wings (Fig. 98) and one additional setigerous puncture on margin of head (Fig. 100).

\section{Key to the species of Blaena}

1. Hemelytra conspicuously shortened, membrane strongly reduced (Figs 29, 97)

- Hemelytra normally developed, membrane large (Figs 19, 28, $33,49,58,68,79,98)$

2. Small species, body length not exceeding $3.0 \mathrm{~mm}$; membran strongly reduced, narrow (Fig. 97); lateral margins of pronotum with 5-6 submarginal setigerous punctures bearing hair-like setae B. tamasi J.A. Lis
- Large species, body length exceeding $3.0 \mathrm{~mm}(3,55-4,20)$; membrane large, flap-like (Fig. 29); lateral margins of pronotum with $8-10$ submarginal setigerous punctures bearing hair-like setae ............... B. hirta sp. n.

3. Pronotum strongly and broadly constricted in the middle (Fig. 19,21) ................ coarctata Froeschner

- Pronotal margins straight or only slightly sinuate in the middle

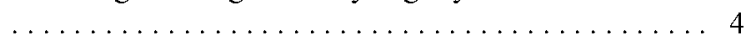

4. Lateral margins of pronotum not serrated (Figs 2, 11, 42, 49, $51,58,62,79,83$ ), or with $1-2$ projections (Figs 33, 35, 91)

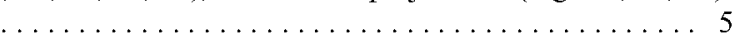

- Lateral margins of pronotum strongly serrated, with numerous (4-11) small sharp denticles (Figs 28, 31, 68, 71, 98, 101) 


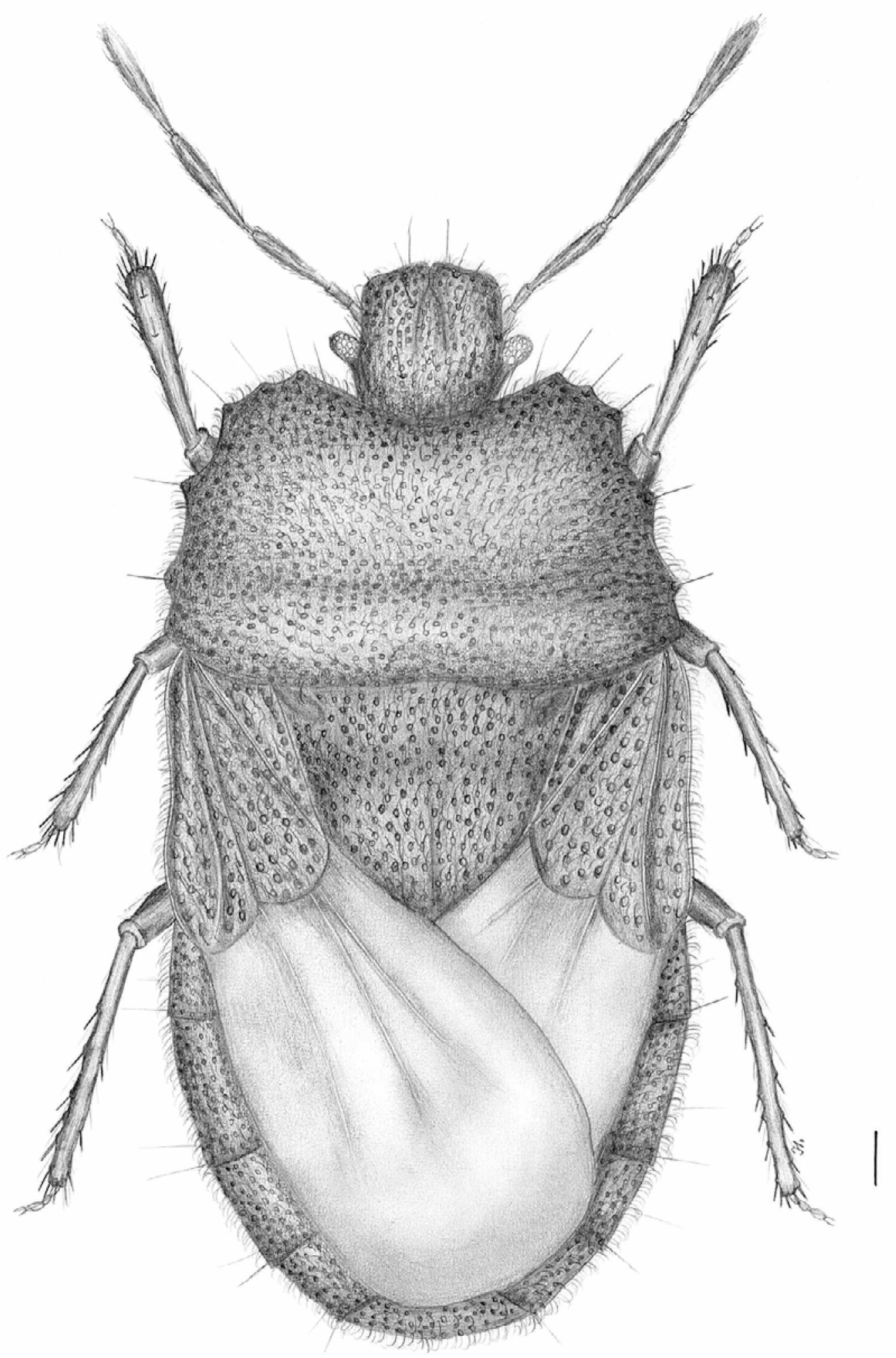

Fig. 98. Blaena tamasi J.A. Lis, macropterous form - dorsal view. Scale: $0.15 \mathrm{~mm}$. 

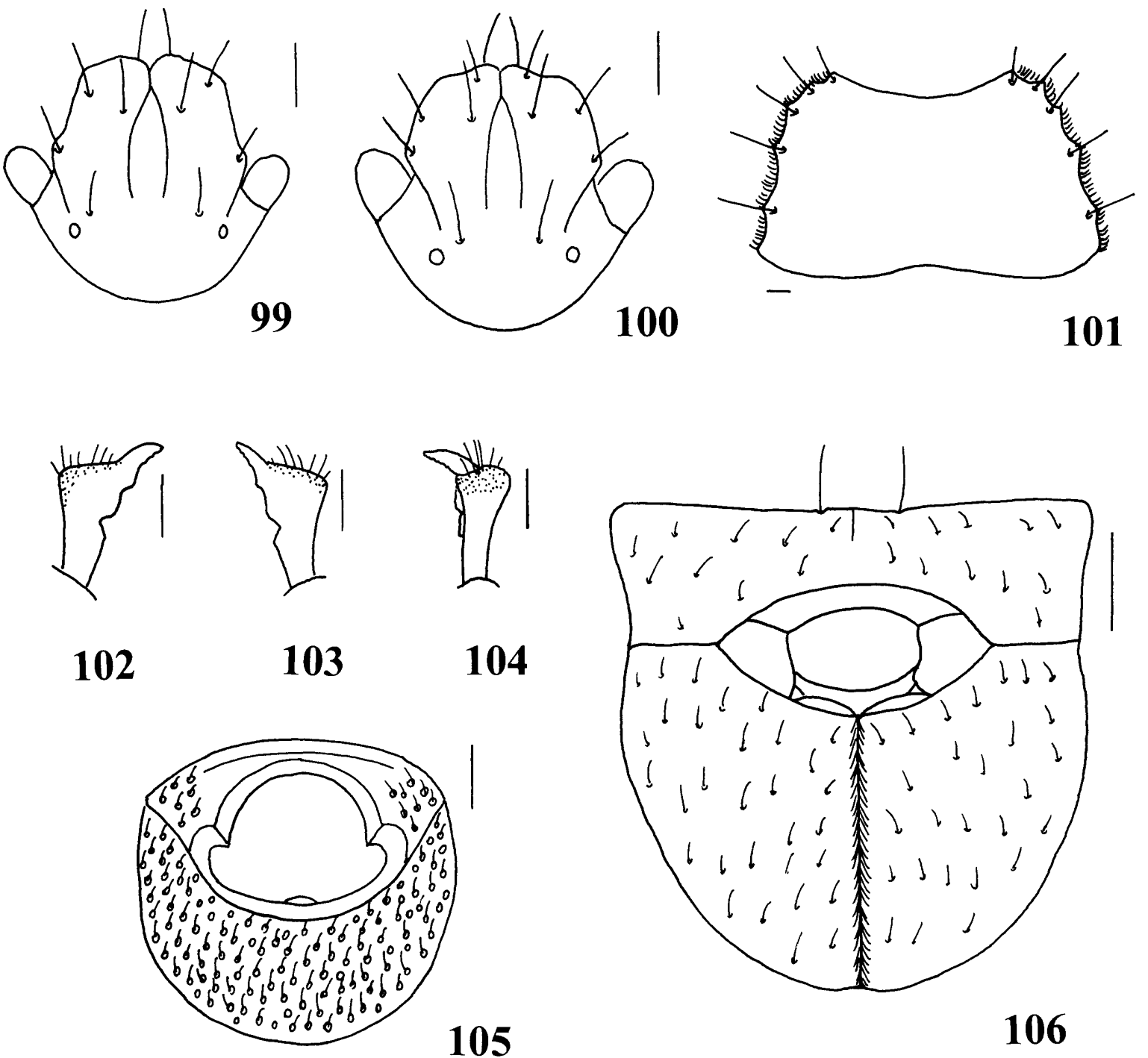

Figs 99-106. Blaena tamasi J.A. Lis. 99-100 - head; 101 - pronotum; 102-104 - various views of paramere; 105 - male genital capsule; 106 - female genital plates. Scale: $0.1 \mathrm{~mm}$.

5. Costal margin without setigerous punctures bearing hair-like setae; paraclypei forming a strong, irregular ridge on either side of clypeus $\ldots \ldots \ldots \ldots \ldots \ldots \ldots$

- Costal margin with 4-17 setigerous punctures bearing hair-like setae; paraclypei without irregular ridge on either side of

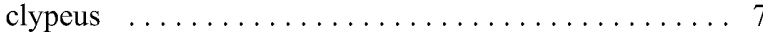

6. Lateral margins of pronotum strongly explanate, each bearing 2 submarginal setigerous punctures, one on anterior lobe, one on the prebasal projection of posterior lobe (Figs 33, 35); median carina on pronotum and scutellum welldeveloped, convex and impunctate (Fig. 33); scutellum with deep lateral impression on either side of carina, and clear elevated tuberosity anteriorly; small species $(4.70-5.20 \mathrm{~mm}$ in length) ............ B. mediocarinata Froeschner

- Lateral margins of pronotum not explanate, each bearing 5-6 submarginal setigerous punctures, $4-5$ on anterior lobe, one on the small prebasal projection of posterior lobe (Fig. 91); median carina on pronotum and scutellum hardly visible or absent; scutellum with shallow lateral impression on either side of carina, and lacking tuberosity anteriorly; large species (5.75-6.30 $\mathrm{mm}$ in length) . . B. subsulcata Froeschner
7. Furrow along lateral margins of abdominal sterna deep and conspicuous; body margins with less numerous setigerous punctures bearing long hair-like setae (head 3 , pronotum 9-13, costal margin 4-6) . . . . . . . . B. setosa Walker

- Furrow along lateral margins of abdominal sterna shallow, hardly visible or totally absent; body margins with more numerous setigerous punctures bearing long hair-like setae (head 4-6, pronotum 15-23, costal margin 7-17) ... . 8

8. Prosternal carinae distinct and high, their apical parts forming conspicuously delimited ridges, rostral trough as deep as height of the 2nd segment of rostrum $\ldots \ldots \ldots \ldots .9$

- Prosternal carinae vague or only slightly elevated, their apical parts not forming conspicuously delimited ridges, rostral trough shallow $\ldots \ldots \ldots \ldots \ldots \ldots \ldots \ldots \ldots . \ldots 10$

9. Prosternal carinae densely covered with short woolly hairs; male posterior femur with a row of short spines, male posterior tibia strongly recurved apically (Fig. 52) .......... $\ldots \ldots \ldots \ldots \ldots \ldots \ldots$. . parathroposa sp. n.

- Prosternal carinae bare or with single short hairs; male posterior femur with 3-4 strong spines, male posterior tibia

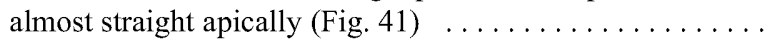

B. multitricha Froeschner 
10. Prosternal carinae, as well as anterior margins of propleura bearing numerous golden woolly hairs; male hind femur with a row of strong spines, among these at least one clearly larger than the others (Fig. 12) .... B. cirra Froeschner

- Prosternal carinae, as well as anterior margins of propleura bare or bearing a few hardly visible hairs; male hind femur with a row of similar sized spines (Fig. 61) ....... 11

11. Male middle femur with a row of acute tubercles on posteroventral margin; male hind tibia ventrally with a row of tubercles on each margin (Fig. 3)

Male middle femur with a row of strong large spines on posteroventral margin (Fig. 60); male hind tibia ventrally with a row of large and sharp, apically downcurved spines on each margin (Figs 58,61) ......... B. pseudosetosa $\mathrm{sp.} \mathrm{n.}$

12. 2nd antennal segment longer than the 1st segment; body surface without woolly hairs; females with small spines on femora II and III; costal margin with $10-13$ setigerous punctures bearing hair-like setae ......... B. serrata $\mathrm{sp.} \mathrm{n}$

- 2nd antennal segment decidedly shorter than the 1st segment; body surface bearing woolly hairs; females without spines on femora; costal margin without setigerous punctures .... $\ldots \ldots \ldots \ldots \ldots \ldots \ldots \ldots \ldots \ldots \ldots \ldots \ldots \ldots$

13. Lateral margins of pronotum with $8-10$ denticles with setigerous punctures bearing long setae; large species, body length clearly exceeding $3.0 \mathrm{~mm} \ldots \ldots \ldots$. hirta $\mathrm{sp}$. n.

- Lateral margins of pronotum with 5-6 denticles with setigerous punctures bearing long setae; small species, body length not exceeding $3.0 \mathrm{~mm} \ldots \ldots$. . tamasi J.A. Lis

ACKNOWLEDGEMENTS. We are sincerely grateful to the following for arranging loans of the material for this study: $M$ Webb (BMNH), K. Kami (BPBM), R. Storey (QPIM), T. Vásárhelyi (HNHM), H. Zettel (NHMW), V. Śvihla (NMPC), K Walker (MVNH), G. Brown (MAGD), G. Monteith (QMBA), J. Forrest (SAMA), M. Schneider (UQIC), T. F. Houston (WAMP), I. M. Kerzhner (ZMAS).

\section{REFERENCES}

Distant W.L. 1899: Rhynchotal notes-Heteroptera: Plataspinae, Thyreocorinae and Cydninae. Annals and Magazine of natural History (Ser. 7) 4: 213-227.

Froescrner R.C. 1960: The genus Blaena Walker (= Macrymerus Signoret) with the description of four new species and a key to the known forms (Hemiptera: Cydnidae). Records of the South Australian Musem 13: 453-466.

FroEsChNER R.C. 1966: Two new species of the Australian genus Blaena with notes on previously described species (Hemiptera: Cydnidae). Journal of the Kansas entomological Society 39: 690-694.

LIs J.A. 1994: A revision of Oriental burrower bugs (Heteroptera: Cydnidae). Upper Silesian Museum, Department of Natural History, Bytom, 349 pp.

Lis J.A. 1995: A synonymic list of burrower bugs of the Australian Region (Heteroptera: Cydnidae). Genus (Wroclaw) 6: 137-149.

Lrs J.A. 1996: A review of the burrower bugs of the Australian Region, with a discussion on the distribution of the genera (Hemiptera: Heteroptera: Cydnidae). Genus (Wrocław) 7: 177-238.

Lis J.A. 1997: Three new Australian genera of burrower bugs with four new species (Heteroptera: Cydnidae). Polskie Pismo entomologiczne 66: 189-201.

Lis J.A. 1999a: Blaena tamasi sp. n. from Western Australia, the first species of Cydnidae (Hemiptera: Heteroptera) with staphylinoid wing modification. European Journal of Entomology 96: 53-55.

LIS J.A. 1999b: Burrower bugs of the Old World - a catalogue (Hemiptera: Heteroptera: Cydnidae). Genus (Wroclaw) 10: $165-249$.

SignORET V. 1880a: (Note). Bulletin de la Société entomologique de France (so called Bulletin Bimensuel) 1880: p. 25.

Signoret V. 1880b: (Note). Annales de la Société entomologique de France, Bulletin entomologique (Ser. 5) 10: 17-18.

WALKER F. 1868: Catalogue of the Specimens of Hemiptera Heteroptera in the Collection of the British Museum 3. British Museum (Natural History), London, 538 pp.

Received December 6, 2000; February 15, 2001; accepted April 10, 2001 